\title{
Accurate in vivo population sequencing uncovers drivers of within-host genetic diversity in viruses
}

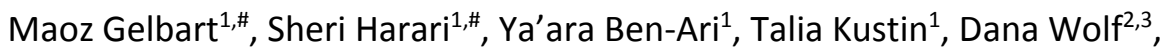 \\ Michal Mandelboim ${ }^{4,5}$ Orna Mor ${ }^{4,6}$, Pleuni Pennings ${ }^{7}$, Adi Stern ${ }^{1, *}$
}

${ }^{1}$ School of Molecular Cell Biology and Biotechnology, George S. Wise Faculty of Life Sciences, Tel Aviv University, Tel Aviv, Israel

${ }^{2}$ Clinical Virology Unit, Hadassah Hebrew University Medical Center, Jerusalem, Israel

${ }^{3}$ The Lautenberg Center for General and Tumor Immunology, IMRIC, the Faculty of Medicine, the Hebrew University, Jerusalem, Israel

${ }^{4}$ Central Virology Laboratory, Ministry of Health, Sheba Medical Center, Ramat-Gan, Israel.

${ }^{5}$ Department of Epidemiology and Preventive Medicine, School of Public Health, Sackler Faculty of Medicine, Tel Aviv University, Tel Aviv, Israel

${ }^{6}$ Sackler School of Medicine, Tel Aviv University, Tel Aviv, Israel.

${ }^{7}$ Department of Biology, San Francisco State University, San Francisco, CA, USA

\footnotetext{
\# Authors contributed equally

* To whom correspondence should be addressed. Email: sternadi@tau.ac.il
} 


\section{ABSTRACT}

2 Mutations fuel evolution and facilitate adaptation to novel environments. However,

3 characterizing the spectrum of mutations in a population is obscured by high error rates of next

4 generation sequencing. Here, we present AccuNGS, a novel in vivo sequencing approach that

5 detects variants as rare as 1:10,000. Applying it to 46 clinical samples taken from early infections

6 of the human-infecting viruses HIV, RSV and CMV, revealed large differences in within-host

7 genetic diversity among virus populations. Haplotype reconstruction revealed that increased

8 diversity was mostly driven by multiple transmitted/founder viruses in HIV and CMV samples.

9 Conversely, we detected an abundance of defective virus genomes (DVGs) in RSV samples,

10 including hyper-edited genomes, nonsense mutations and single point deletions. Higher

11 proportions of DVGs correlated with increased viral loads, suggesting increased cellular co-

12 infection rates, which enable DVG persistence. AccuNGS establishes a general platform that

13 allows detecting DVGs, and in general, rare variants that drive evolution. 


\section{INTRODUCTION}

Viruses are among the fastest evolving entities on earth. Thanks to short generation times, large population sizes and high mutation rates, viruses and in particular RNA viruses rapidly accumulate genetic diversity. This genetic diversity is key to successful adaptation of viruses to novel challenges such as the immune system and drugs (Duffy, et al. 2008). The short time window following virus transmission, termed acute infection, is extremely critical for virus populations: they must develop their arsenal of genetic diversity to either escape from the immune system, evade drugs or adapt to a new environment (possibly even a new host) (Parrish, et al. 2008). While we know that many genetic variants are created in this critical time window - the vast majority of these variants segregate at low frequencies that approach the mutation rate of the virus, and are completely undetectable using current next generation sequencing (NGS) approaches (Acevedo, et al. 2014). In fact, these variants will only be discovered after they reach high frequencies, when they will already exert a deleterious effect on the host. For example, today we are only able to detect an HIV drug resistance mutation when it is at a relatively high frequency, after resistance phenotype is observed and already unpreventable (Ram, et al. 2015; Boucher, et al. 2018; Döring, et al. 2018). The naturally occurring frequency of drug resistance mutations could also allow us to infer the fitness cost of these mutations in the absence of drugs (Theys, et al. 2018). An additional long-standing question in the field of virus evolution is the measurement of mutation rates, which also requires accurate sequencing (Acevedo, et al. 2014; Zanini, Puller, et al. 2017). Thus, an accurate sequencing method that maintains high yield is required to thoroughly study evolving populations.

Accurate population sequencing is critical in many different disciplines including genetics, immunology and microbiology as well as tumor screening and prenatal diagnosis. However, using the standard NGS protocols may result in significant background error rates. In fact, following typical post-processing of NGS data, genetic variants that are measured at frequencies lower than 1-5\% are discarded (Meacham, et al. 2011; Casadella and Paredes 2017; Huber, et al. 2017; McCrone, et al. 2018). In the past few years, several innovative approaches were suggested to reduce the background error rates of the NGS process: rolling-circle-based redundant coding of the amplified fragments (Lou, et al. 2013; Acevedo, et al. 2014; Reid-Bayliss and Loeb 2017; Wang, et al. 2017); consensus sequencing of barcoded genomic fragments (Jabara, et al. 2011; Kennedy, et al. 2014; Zhou, et al. 2015; Jee, et al. 2016; Newman, et al. 
2016; Wang, et al. 2017); error reduction by overlapping paired reads in paired-end sequencing

47 (Chen-Harris, et al. 2013; Schirmer, et al. 2015; Preston, et al. 2016); and usage of improved

48 polymerases (Imashimizu, et al. 2013). However, most experimental methods described above

49 are designed for samples with high biomass and are inapplicable for sequencing of clinical

50 samples, where the biomass may be extremely low. Furthermore, these experimental protocols

51 may introduce their own artifacts to the sequencing process (Lou, et al. 2013; Brodin, et al.

52 2015). On the computational side, it has been suggested that well-established variant callers do

53 not perform well on clinical virus samples (McCrone and Lauring 2016). Here, we sought to

54 develop a simple and rapid approach that can tackle the problem of accurate sequencing of

55 clinical samples, and applied it to study the early stages of virus infection.

56 We describe AccuNGS, a simple yet powerful approach for accurate population sequencing and

57 bioinformatics variant calling. We extensively optimize all stages of the method to ensure high

58 accuracy and maximal yield. We use AccuNGS to perform in-depth sequencing of 46 samples

59 from three different major human pathogenic viruses: human immunodeficiency virus (HIV),

60 respiratory syncytial virus (RSV), and cytomegalovirus (CMV), all sampled during the acute

61 infection stage. We compare the within-host genetic diversity among and within different virus

62 populations, and find patterns characteristic of each virus. We demonstrate the role of multiple

63 transmitted/founder viruses as major contributors to the genetic diversity in HIV and CMV.

64 Furthermore, we identify and quantify the impact of various host editing enzymes on the

65 mutational spectrum of viral genomes/populations in vivo. Intriguingly, we find that RSV

66 samples bear much higher levels of potentially defective virus genome (DVGs) than the two

67 other viruses analyzed herein. Finally, we propose a link between the level of DVGs in a

68 population and the levels of cellular co-infection.

\section{RESULTS}

\section{An overview of the AccuNGS sequencing approach}

71 We have developed a new sequencing approach called AccuNGS, designed to maximize both the

72 accuracy of variant calling and template recovery. To achieve this, several key concepts were put

73 together: (i) usage of high-yield and high-fidelity polymerases to increase yield and reduce error

74 rates; (ii) sequencing error reduction through overlapping paired end reads; (iii) minimization of

75 template loss across different stages of the protocol, (iv) statistical modeling of error rates using

76 a control that forms the heart of a computational pipeline for variant calling and inference of 
77 variant frequency (Fig. 1). We first extensively optimized the different experimental stages of

78 the protocol, by testing the accuracy of sequencing a clonally derived plasmid (Methods). This

79 allowed us to assess the contribution of the various stages to the error rate of the protocol

80 (Supplementary text, Fig. S1, Tables S1-S5). We were able to (a) mostly rule out the contribution

81 of PCR to error rates (Zanini, Brodin, et al. 2017), (b) note that the two reads generated by the

82 sequencer are dependent observations, and (c) reveal that AccuNGS is likely limited by the

83 accuracy of the sequencing machine itself (which we cannot affect) (Supplementary text, Fig.

84 S1B). We conclude that the mean error rate for transitions and transversions that is achieved by

85 AccuNGS is a little lower than $10^{-4}$ and $10^{-5}$, respectively, and varies by types of mutation (Table

86 1). This allows us to statistically call variants that are as rare as $10^{-4}$, which we further verified by

87 creating synthetic mixtures of two different HIV plasmids at different proportions and

88 sequencing them (Fig. S2).

89 Initially we used a barcoding approach (Jabara, et al. 2011) to estimate the number of viral

90 genomes we sequenced for one of the HIV clinical samples, allowing us to estimate that we had

91 sequenced $\sim 15,000$ separate genomes (Supplementary text). While it was reassuring that we

92 sequenced a large number of genomes, we also showed that the mere addition of a barcode led

93 to a reduction in the number of sequenced templates (Supplementary text, Fig. S3). In other

94 words, we found that without a barcode we sequence more genomes, but we cannot count how

95 many. We henceforth avoided the use of barcoding. Finally, we would like to emphasize that

96 while the average error rate of AccuNGS is very low, sampling and PCR biases may lead to a

97 given variant being detected at a lower or higher frequency than it should be (Illingworth, et al.

98 2017; Zhao and Illingworth 2019). This is especially true when the number of input templates is

99 low. We thus conclude that AccuNGS is useful for inferring average rates and average

100 frequencies (e.g., premature stop codons as elaborated below) rather than inferring the exact

101 frequency of one given variant in a given sample. 


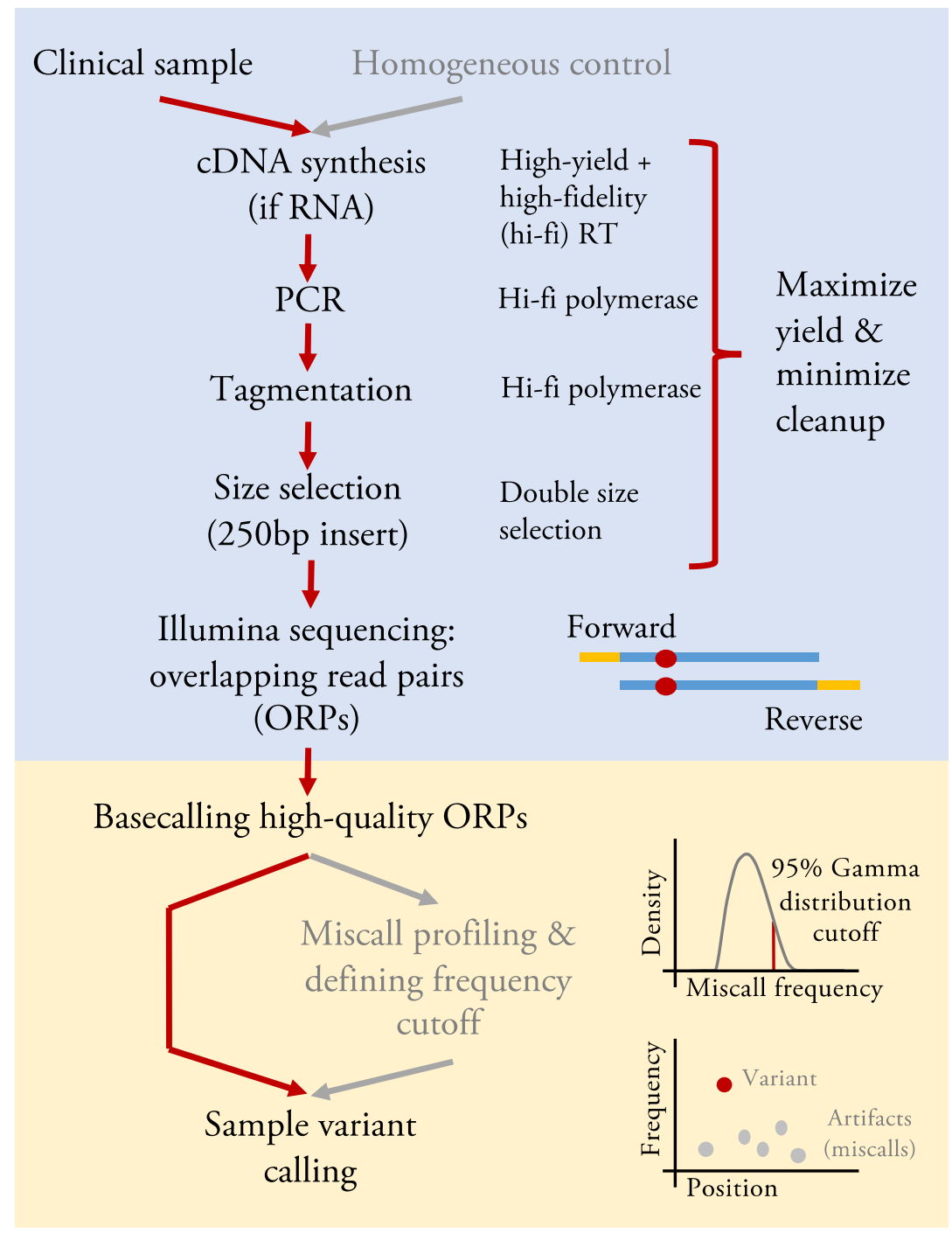

Fig. 1. AccuNGS principles. The protocol requires side by side targeted sequencing of a biological sample together with a homogenous control (e.g., a plasmid encoding for the same genomic region sequenced in the sample). Stages of the protocol include: (i) High-fidelity and high-yield RT reaction, (ii) High-fidelity PCR reaction, (iii) Tagmentation and library construction with size selection for an insert the size of a single paired-end read, (iv) Paired-end sequencing where each base in the insert is sequenced twice, once in the forward read and again in the reverse read ,(v) Alignment of reads, Q-score filtering on both reads and base-calling of both the sample and a homogeneous control, and (vi) Sample variant calling based on gamma distributions that are fitted to the process errors, defined as mutations found in the

Table 1. Error rates for AccuNGS. Shown are parameters for fitted gamma distributions given a Q30 score cutoff. Transitions are shaded in darker gray than transversions. 


\begin{tabular}{|c|c|c|c|c|c|}
\hline $\begin{array}{l}\text { Error } \\
\text { type }\end{array}$ & Shape (к) & Scale $(\theta)$ & $\begin{array}{l}95^{\text {th }} \text { percentile } \\
\text { of distribution }\end{array}$ & $\begin{array}{c}\text { Mean error } \\
\text { rate }^{\mathrm{a}}\end{array}$ & $\begin{array}{c}\text { Median error } \\
\text { rate }^{\mathrm{a}}\end{array}$ \\
\hline$A->G$ & 7.292 & 8.51E-06 & $1.04 \mathrm{E}-04$ & $6.21 \mathrm{E}-05$ & $6.0 \mathrm{E}-05$ \\
\hline$C->T$ & 3.349 & $1.27 \mathrm{E}-05$ & 8.70E-05 & 4.27E-05 & $3.8 \mathrm{E}-05$ \\
\hline G->A & 4.026 & $1.22 \mathrm{E}-05$ & 9.51E-05 & 4.91E-05 & 4.6E-05 \\
\hline$T->C$ & 6.704 & $9.80 \mathrm{E}-06$ & $1.12 \mathrm{E}-04$ & 6.57E-05 & 6.3E-05 \\
\hline$A>C$ & 3.295 & 2.27E-06 & $1.52 \mathrm{E}-05$ & 7.48E-06 & $6.0 \mathrm{E}-06$ \\
\hline$A>T$ & 2.709 & $1.63 \mathrm{E}-05$ & 9.54E-05 & 4.41E-05 & 4.0E-05 \\
\hline$C>A$ & 2.149 & 8.70E-06 & 4.33E-05 & $1.86 \mathrm{E}-05$ & $1.4 \mathrm{E}-05$ \\
\hline $\mathbf{C}>\mathbf{G}$ & 3.747 & $2.74 \mathrm{E}-06$ & $2.02 \mathrm{E}-05$ & $1.02 \mathrm{E}-05$ & $9.0 \mathrm{E}-06$ \\
\hline G>C & 3.810 & 2.95E-06 & $2.21 \mathrm{E}-05$ & $1.12 \mathrm{E}-05$ & $1.0 \mathrm{E}-05$ \\
\hline$G>T$ & 3.095 & 5.70E-06 & 3.67E-05 & $1.76 \mathrm{E}-05$ & $1.6 \mathrm{E}-05$ \\
\hline$T>A$ & 2.874 & $1.21 \mathrm{E}-05$ & 7.41E-05 & $3.48 \mathrm{E}-05$ & 3.3E-05 \\
\hline $\mathbf{T}>\mathbf{G}$ & 2.342 & $3.51 \mathrm{E}-06$ & $1.85 \mathrm{E}-05$ & 8.22E-06 & 6.0E-06 \\
\hline
\end{tabular}

$116{ }^{a}$ Calculated based on the raw frequencies of mutations found in the baseline control.

\section{Accurate sequencing of different virus populations during acute/early infections}

118 We obtained a total of 46 samples from patients recently infected by the RNA viruses HIV and 119 RSV, and the DNA virus CMV (Table 2, Table S6). We focused our sequencing efforts mostly on 120 conserved genes, precisely since we expect less diversity and we wanted to test our ability to 121 detect rare "hidden" variants that are otherwise unobservable. Hyper-variable genes such as the 122 HIV-1 envelope have been sequenced extensively using other sequencing approaches (e.g., 123 Keele, et al. 2008; Salazar-Gonzalez, et al. 2008; Zhou, et al. 2016), and the presence of high 124 frequency variants is not surprising in such genes. We thus chose the Gag-Pol open reading 125 frame for HIV, the M2 and L open reading frame (encoding for the viral polymerase) for RSV, 126 and the UL54 (also encoding for the viral polymerase) for CMV. In order to allow for comparison, 127 we also sequenced the F and G envelope glycoproteins genes in RSV, and further compared our 128 results to previous sequencing results of the envelope gene in HIV.

129 Each sample underwent population sequencing and variant calling using AccuNGS (see

130 Methods). We began by calculating the total nucleotide diversity $\pi$ in each sample based on the 131 transition variants (Methods). This revealed different distributions of diversity within and 132 between viruses (Fig. 2A). In the HIV populations, diversity values spanned several orders of 
133 magnitude. On the contrary, RSV populations exhibited very similar intermediate levels of

134 diversity. Similarly, CMV populations usually displayed the lowest diversity with the exception of

135 one sample. We set out to understand what factors drive the differences in diversity among the

136 different samples.

137 Table 2. Details of samples sequenced from clinical virus samples.

\begin{tabular}{lllll}
\hline Virus & \#Samples & Samples' origin & $\begin{array}{l}\text { Estimated weeks post } \\
\text { infection }\end{array}$ & $\begin{array}{l}\text { Region sequenced } \\
\text { (NCBI ID) }\end{array}$ \\
\hline HIV & 9 & Plasma & $2-5$ & $532: 3280$ (K03455) \\
RSV & 25 & Nasal/throat & $<1$ & $4640-14350$ (U39661) \\
& & swabs & & $78200-81912$ (NC_006273) \\
CMV & 12 & Amniotic fluid / & $>=4$ & \\
& & Urine / saliva & &
\end{tabular}

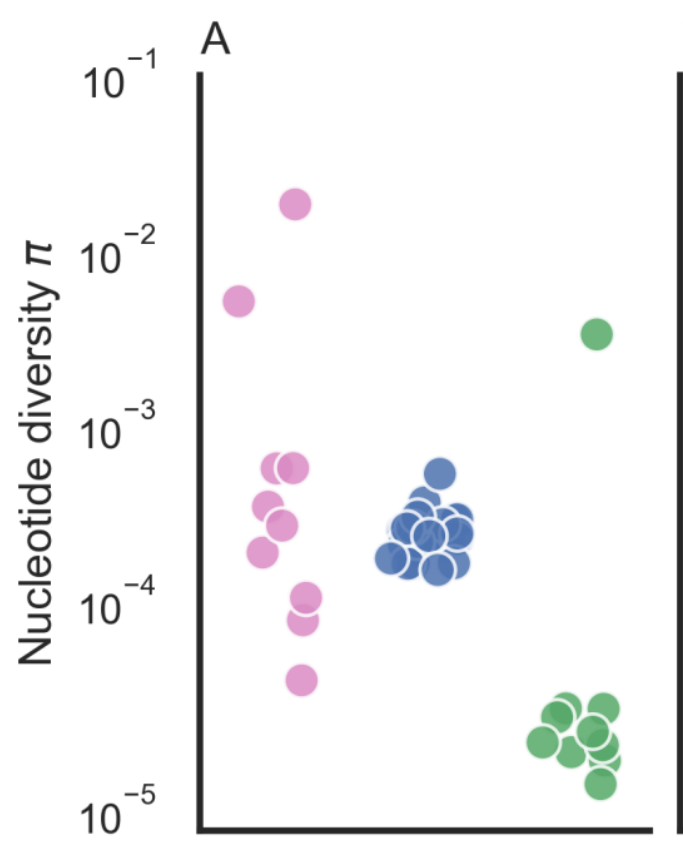

$\mathrm{B}$

$\begin{array}{cccccccccc}\text { HIV } & \text { RSV } & \text { CMV } & \text { HIV } & \text { HIV } & \text { RSV } & \text { RSV } & \text { RSV } & \text { RSV } & \text { CMV } \\ (n=9) & (n=25) & (n=10) & \text { gag } & \text { env } & \text { G } & \text { F } & \text { M2 } & \text { L } & \text { UL54 }\end{array}$

Fig. 2. Nucleotide diversity $\pi$ for acute infections across different virus samples and genes. (A) values were calculated using transition mutations only. (B) Gene by gene breakdown of nucleotide $\pi$ diversity. Values for HIV envelope (squares) were taken from previously published 144 data (Salazar-Gonzalez, et al. 2008). 


\section{Mutation and selection}

146 We first considered the two most evident evolutionary causes of differences in diversity:

147 mutation and selection. First, when considering the mutation rate of a virus, it is clear that the

148 only DNA virus in our data has much lower mutation rates than RNA viruses (Sanjuan, et al.

149 2010) and indeed displays lower diversity. The two RNA viruses display more diversity than the

150 DNA virus CMV, but the variation in diversity levels is much higher in HIV than in RSV.

151 We further considered whether differences in selection pressure cause the variation in diversity 152 we see among the RNA virus samples. This was unlikely to cause within-virus differences, since 153 we sequenced the same set of genes within each of the virus samples. We did note that the 154 immunogenic envelope proteins in this study (HIV Env and RSV G proteins), known to be under 155 positive selection (Seibert, et al. 1995; Nielsen and Yang 1998; Tan, et al. 2013), displayed on 156 average higher diversity than the conserved genes (Fig. 2B). This is not surprising given that 157 some mutations in envelope proteins will be under positive selection since they allow immune 158 evasion, and hence may reach higher frequencies. However, this could not explain why we saw 159 dramatic differences in diversity in different samples from the same virus when focusing on the 160 same gene (e.g., gag in HIV).

\section{Transmission bottleneck size as a contributor to genetic diversity during acute infections}

162 It has previously been noted that infections initiated by a few different divergent viruses are 163 characterized by higher genetic diversity (Keele, et al. 2008; Cudini, et al. 2019). Visual 164 inspection of our frequency plots (Fig. 3, Fig. S4-S6) suggested that often variant frequencies 165 were strongly imbalanced, also evident as "bands" of variants at similar frequencies. For 166 example, sample HIV6 (measured diversity $1.46 \times 10^{-2}$ ) contained many variants segregating at a 167 frequency of $\sim 2 \times 10^{-1}$ yet very few variants segregated at frequencies between $10^{-3}$ and $10^{-1}$ (Fig.

$1683 \mathrm{~A})$. We first considered how likely it is that such a sample would be initiated by only one 169 founder virus/genotype, where all variants begin at a defined frequency of zero. Given a large 170 enough population size and a mutation rate in the order of $10^{-5}$ mutations/site/day (Zanini, 171 Puller, et al. 2017), we expect neutral variants that are likely generated over and over almost 172 every day to roughly reach a frequency of $10^{-4}-10^{-3}$ after a few weeks of infection, which is much 173 lower than $10^{-1}$. Genetic drift or positive selection could drive a few variants to increase in 174 frequency over a short time; however, it seems extremely unlikely that there is such a large set 175 of sites under the exact same regime of positive selection, especially as we had sequenced a 
176 gene where positive selection is all in all less prevalent, at least this early in the course of the

177 infection. Thus, it seems quite unlikely that very high diversity samples containing many high

178 frequency variants are founded by one virus genotype, and a more likely explanation is the

179 presence of multiple transmitted/founder viruses.
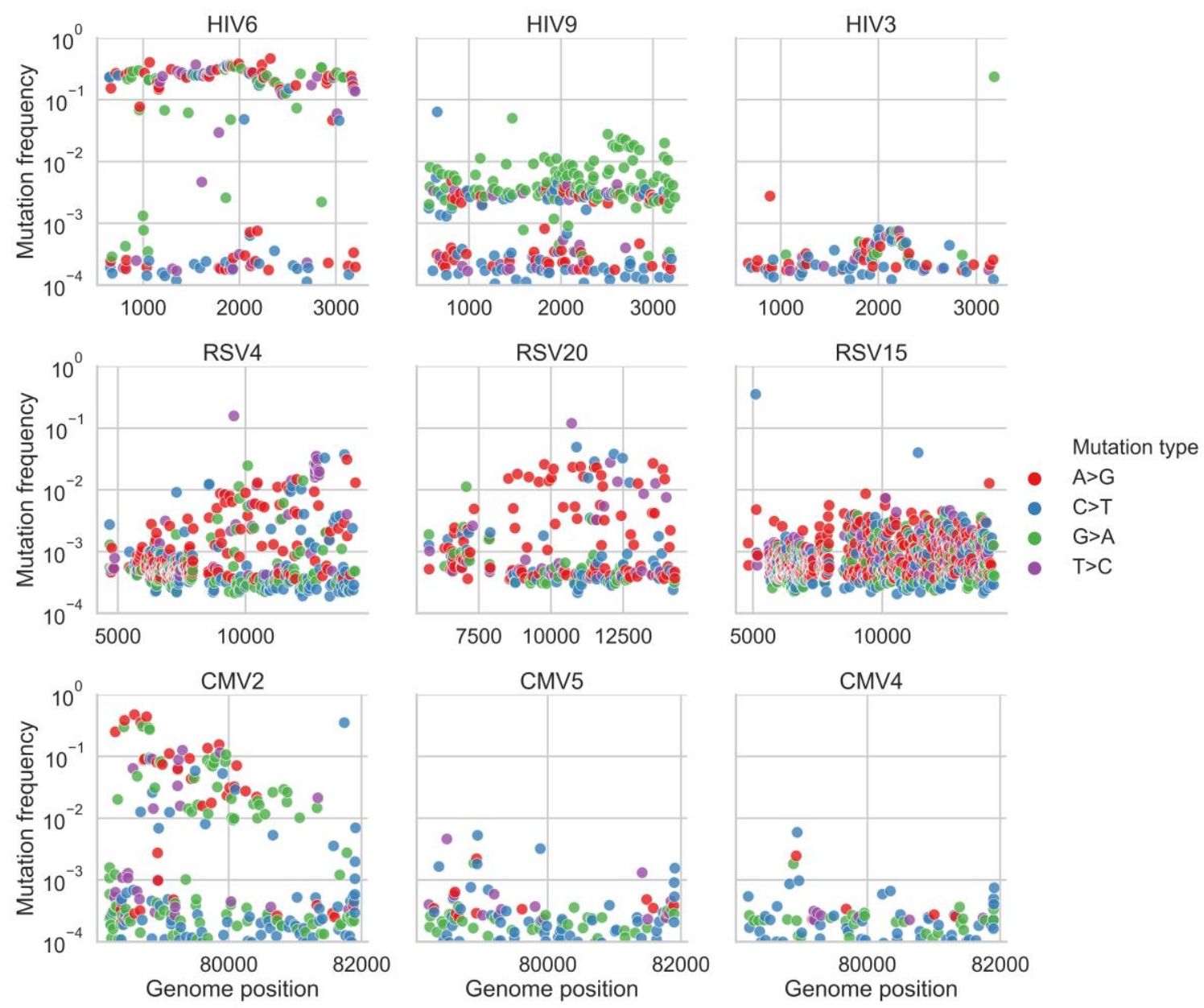

Figure 3. Variants frequency plots in representative samples. Shown are frequencies of transition variants called by AccuNGS, for representative samples from each virus (HIV, top row, RSV, middle row, CMV, bottom row). Samples exemplify multiple founder infections, mutation biases, and relatively homogenous populations (see text for details).

To evaluate the number of founder viruses we require an estimation of the different haplotypes present in a sample, and their abundances. However, reconstruction of virus haplotypes from short reads and from one time-point is a longstanding problem (Schirmer, et al. 2014). This is 
due to two conflicting features of viral population sequencing data: on the one hand, the data is often too homogenous. In other words, most reads are identical or almost identical to the consensus, and there may not be enough variants on one read that allow "linking" it with another read. On the other hand, the mutation rates of viruses may scale with sequencing error rates, throwing off most commonly used haplotype reconstruction methods.

Two major advantages of our data are the much higher accuracy of AccuNGS, coupled with very high sequencing depth. We thus set out to develop a new approach for inferring viral haplotypes. Instead of attempting to reconstruct the entire haplotype, we mainly focused on inferring if more than one haplotype (and hence more than one founder virus in our case) is present in a sample. Our approach is based on looking for statistical enrichment for two variants being present on the same read as opposed to each variant on its own, and then linking these reads one with another based on shared variants (Methods) (Yang, et al. 2013). To validate our approach, we used the samples where we had synthetically mixed two plasmids and discovered that all and only true variant sites were identified as linked to each other in with an accurately estimated frequency of 1:10,000 (Fig. S7). Importantly, this confirmed that AccuNGS does not suffer from various artifacts such as PCR recombination that could break linkage between adjacent sites, and that even a rare haplotype can be inferred.

Our haplotype reconstruction approach also led us to realize one of the combined strength and pitfalls of accurate sequencing: we were able to initially detect minute contaminations (a few hundred out of millions of reads) from one sample into another, which we were then able to computationally filter out (Supplementary text). This contamination likely occurred during one of the stages of the library preparation and sequencing, and emphasizes the sensitivity of genomics approaches today, which may often exceed that of the molecular biology itself (Kircher, et al. 2011; Gu, et al. 2019). On the other hand, AccuNGS also allows for the clear-cut detection and evaluation of any contamination, which we believe are very important to capture.

We next applied our haplotype inference flow to all the filtered samples, and found that all of the high diversity samples (total diversity $>10^{-3}$, Fig. $2 \mathrm{~A}$ ) exhibited strong evidence for containing two or more divergent haplotypes (Figs. S4-S6). Two examples are shown in Figs. 3 and 4: HIV sample 6 has a "band" of variant frequencies around $2 \times 10^{-1}$ (Fig. 3), and indeed most of these variants can be linked to each other in this sample (Fig. 4). CMV sample 2 has a wide "band" of variant frequencies between $10^{-2}$ and $5 \times 10^{-1}$ (Fig. 3), which were also mostly found to be linked, 
221 and likely represent a founder haplotype and the associated variants that were created on the

222 background of this haplotype (Fig. 4). In general, we found no evidence for two or more

223 haplotypes in the less diverse samples, except for the most diverse RSV sample that also showed

224 limited evidence of a low frequency haplotype (Fig. S5) (see discussion).

225

226
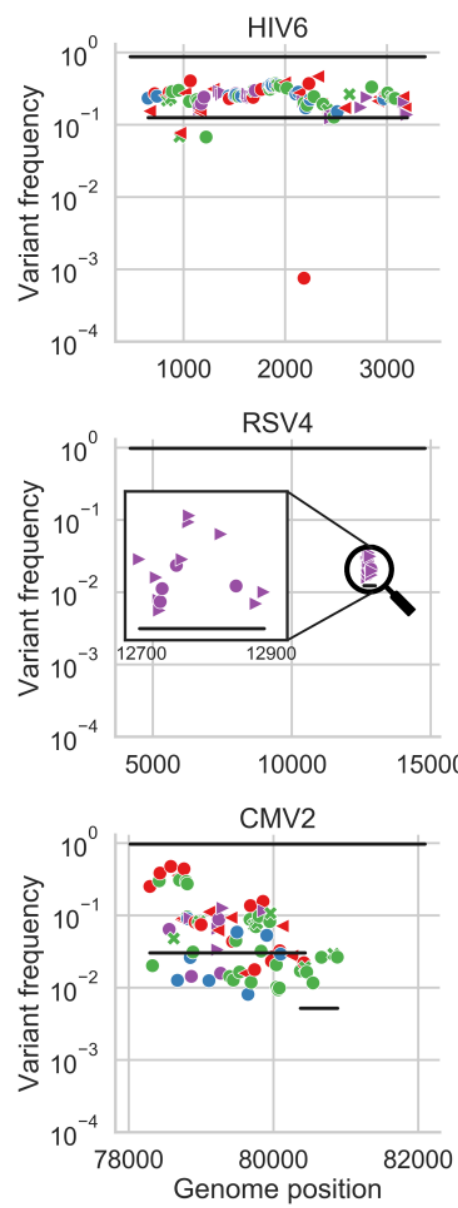
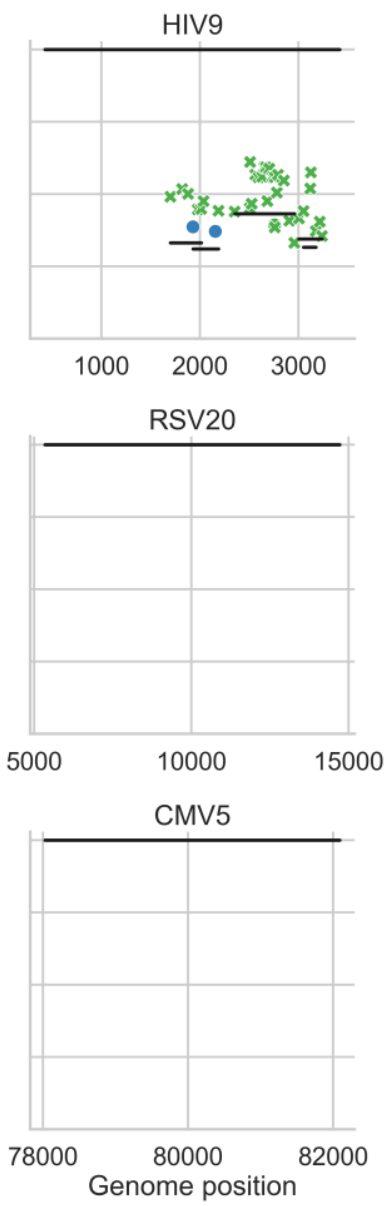
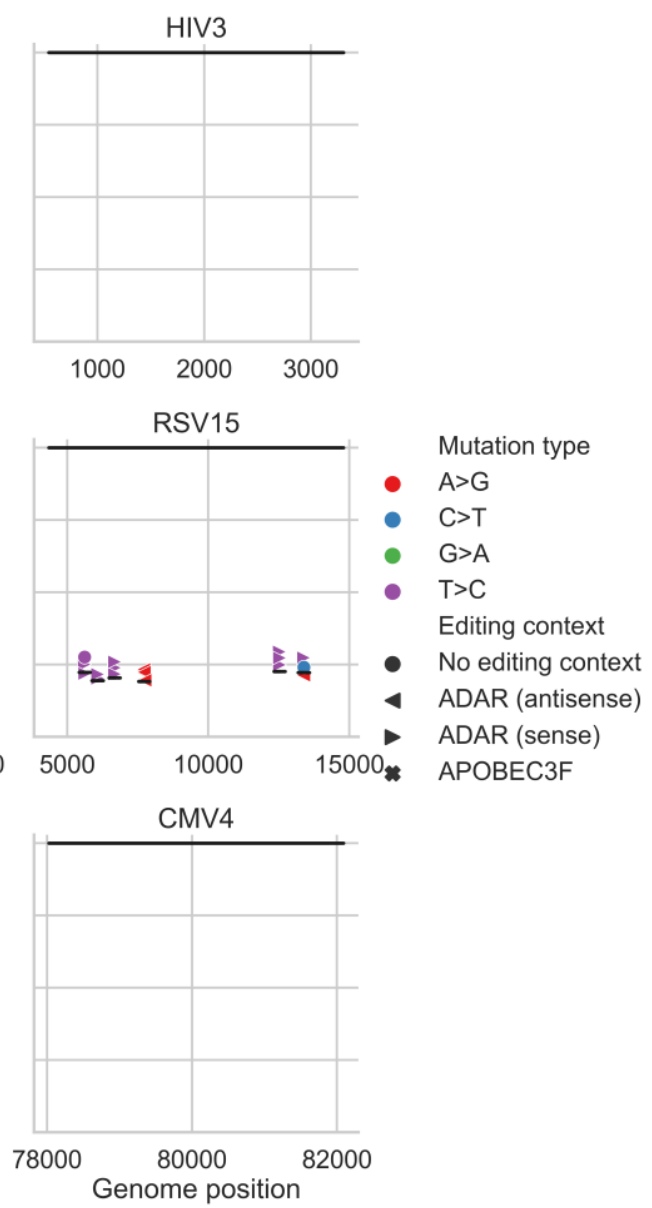

227

Figure 4. Haplotype reconstruction based on co-occurrence of variants on the same reads. Shown are inferred haplotypes (lines) based on consecutive significant associations of pairs of variants (shapes) one to another on the same read. The uppermost line in each panel represents the consensus sequence, which by definition is the major haplotype in each sample. Both HIV6 and CMV2 samples show strong evidence of an additional haplotype, which is likely a second founder genotype. Sample HIV9 shows evidence of G>A hyper-mutation in the context of APOBEC3 editing, samples RSV4 and RSV15 show evidence of T>C or A $>$ G hyper-mutation in the context of ADAR editing in regions spanning a few hundred bases. The hyper-mutated region in RSV4 sample is magnified for clarity. "Empty" panels signify what are likely single haplotype infections, with no evidence of hyper-mutation.

\section{Short hyper-mutated genomic stretches}


238 One well-known phenomenon of HIV infections is the potential of host APOBEC3 (A3) proteins

239 to induce hyper-editing on the negative strand of nascent HIV DNA during reverse transcription,

240 resulting in an excess of G>A mutations in regions of the RNA genome (Hache, et al. 2006;

241 Malim 2009). This hyper-mutation strategy is thought to lead to DVGs that are unable to

242 replicate. However, HIV encodes for a gene called vif that counteracts A3 proteins, and thus

243 most HIV viruses sequenced from blood samples show only minor evidence for A3 activity

244 (Cuevas, et al. 2015). Similarly, the family of human ADAR proteins have also been shown to

245 induce $A>1$ mutations (read as $A>G$ mutations) in a variety of viruses (Samuel 2012). We set out

246 to test if we detect signals of hyper-editing in our samples. In particular we sought to find

247 stretches of hyper-mutations using our haplotype reconstruction approach in order to evaluate

248 whether hyper-editing contributes to the observed genetic diversity, and to what extent.

249 Of all 46 samples, only one HIV sample (HIV9, Fig. 3) displayed strong evidence for G>A hyper-

250 editing. In this sample, editing seemed to be widespread, with multiple distinct and overlapping

251 hyper-mutated genomes (Fig. 4). Hyper G>A mutations were enriched in the context of GpA

252 which is the APOBEC3D/F/H favored editing context but not of the canonical APOBEC3G (Beale,

253 et al. 2004; Bishop, et al. 2004). Most variants on these hyper-mutated stretches were missense

254 variants; some of these stretches contained variants that lead to premature stop codons which

255 are presumably lethal for the virus (Fig. S4). The maximum frequency of such variants in the

256 sample was roughly $2 \times 10^{-2}$. To test whether this occurs due to an inactive vif gene, we

257 sequenced this gene in this sample using AccuNGS. We found no support for this hypothesis

258 since the consensus sequence of this gene was intact, but we once again noticed a relatively

259 high level of G>A mutations in the vif gene itself (Fig. S8). Notably, this sample was taken from

260 the patient with the highest viral load (VL) in our study, which was $>10$ million $\mathrm{cp} / \mathrm{ml}$.

261 Out of 25 independent RSV populations, 11 (44\%) exhibited evidence of ADAR-mediated hyper-

262 edited genomes, manifested as at least three ADAR-associated mutations on the same

263 haplotype (Whitmer, et al. 2018). The presence of ADAR-like hyper-edited haplotypes was

264 positively correlated with viral loads $\left(R^{2}=0.59\right.$; logistic regression; $\left.p<0.0001\right)$, for example all 9

265 samples with measured VL>650k cp/ml contained hyper-mutated inferred haplotypes (Fig. 5D).

266 When observed, ADAR-like linked variants were present at frequencies varying between $\sim 10^{-3}$

267 and $\sim 10^{-2}$, which by far exceed the mutation rate of any known virus. Out of 26 ADAR-like hyper-

268 edited haplotypes, 23 of them were on the negative strand and only 3 were on the positive 
269 strand, in line with previous studies demonstrating that most ADAR-like mutations are acquired

270 on the negative strand of (-)ssRNA viruses (e.g., Whitmer, et al. 2018). Most of the ADAR-like

271 variants on these stretches were missense variants, suggesting they have a detrimental effect on

272 the virus (Fig. S5).

273 None of the CMV populations exhibited any A3, ADAR, or other pattern of hyper-mutation,

274 suggesting that these hyper-mutating enzymes do not act on CMV populations, at least not for

275 the gene sequenced here, or at the level of detection of AccuNGS (but see Weisblum, et al.

276 2017).

\section{Defective virus genomes}

278 Under mutation-selection balance, lethal variants, which are the ultimate DVGs, are expected to 279 segregate at the frequency at which they are generated, which is the mutation rate (Acevedo, et 280 al. 2014; Cuevas, et al. 2015). Based on the expected mutation rates in the viruses we 281 sequenced $\left(<=10^{-4}\right.$ for HIV and RSV, and $\sim 10^{-7}$ for CMV (Sanjuan, et al. 2010)), our initial

282 expectation was that lethal variants should rarely be observed. We were therefore surprised to 283 note the existence of premature stop codons, one of the most obvious forms of a lethal 284 mutation, at a frequency of $10^{-3}-10^{-2}$ in some of the RSV samples (Fig. S5, Fig. S8). All in all we 285 found that RSV substantially differed from the two other viruses with respect to three markers 286 of excess lethal variants: high frequency premature stop codons, high frequency single 287 nucleotide deletions, and presence of hyper-edited haplotypes. RSV had higher proportions of 288 all three types of lethal mutations (Fig. 5A). It thus appears that mutation-selection balance does 289 not necessarily hold for RSV (at least, for some RSV infections). Similar to the presence of hyper290 edited haplotypes for RSV, an excess of stop variants and deletion variants in RSV positively 291 correlated with viral load (VL) (Fig. 5B-D). This raises the possibility that extensive 292 complementation occurs in some RSV samples and in the HIV sample described above, allowing 293 the "rescue" of DVGs through high rates of co-infection. 
bioRxiv preprint doi: https://doi.org/10.1101/349498; this version posted October 10, 2019. The copyright holder for this preprint (which was not certified by peer review) is the author/funder, who has granted bioRxiv a license to display the preprint in perpetuity. It is made available under aCC-BY-NC-ND 4.0 International license.

A

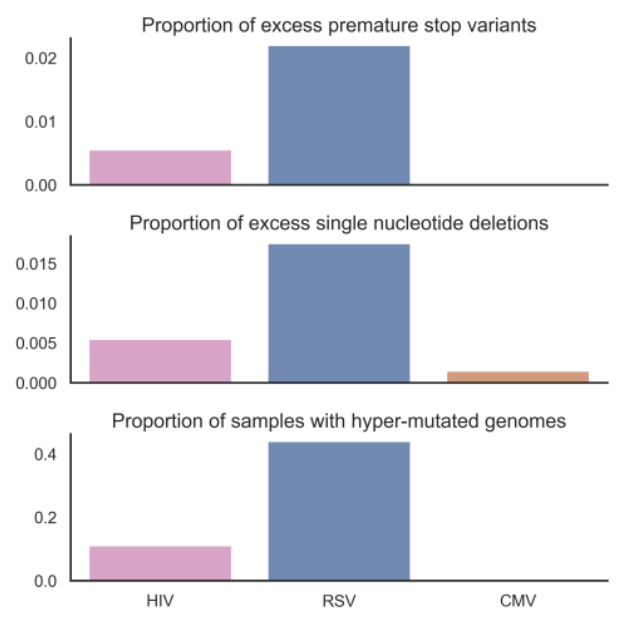

C

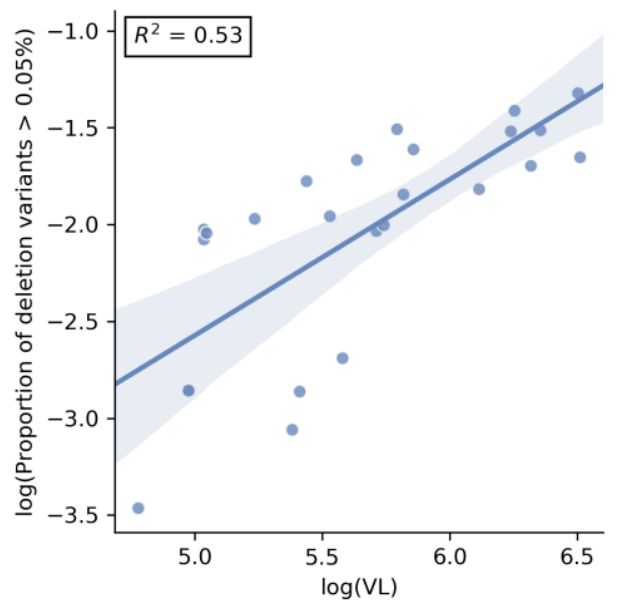

B

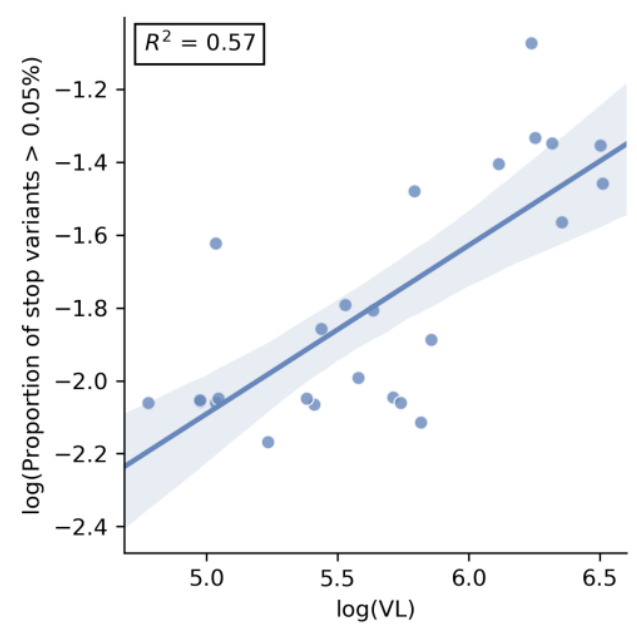

D

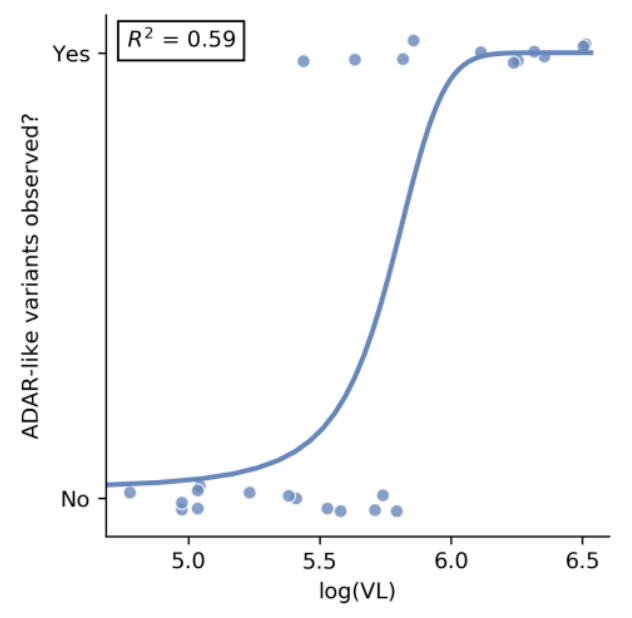

Figure 5. RSV contains high levels of DVGs. (A) Proportion of sites across all samples identified as containing excess lethal variants (top and middle panels), proportion of samples containing at least one hyper-mutated haplotype with a frequency above $5 \times 10^{-4}$ (bottom panel). For RSV, viral load (VL) positively correlated with the (B) excess premature stop codons, (C) excess single nucleotide deletions, and (D) presence of ADAR-like hyper-edited stretches. An excessive lethal variant is defined as one exceeding a frequency of $5 \times 10^{-4}$. (B) and (C) display linear regression lines, whereas (D) displays a logistic regression line. 


\section{DISCUSSION}

306 Application of next generation sequencing to clinical samples is still limited by the ability to 307 reliably capture minor variants (Clutter, et al. 2016; McCrone and Lauring 2016; Boucher, et al.

308 2018). Here we describe AccuNGS, a simple, rapid and accurate experimental protocol and 309 associated computational pipeline for detecting ultra-rare variants from low-biomass clinical

310 RNA and DNA samples. AccuNGS aims to accurately detect minor variants present in a

311 population of genomes at frequencies of 1:10,000 or lower, close to the mutation rate of RNA

312 viruses (Sanjuan, et al. 2010).

313 We used AccuNGS to characterize HIV, RSV, and CMV diversity. The HIV-1 samples were from 314 early stages of infection, typically 2-5 weeks post infection, based on serology testing. The RSV 315 samples were taken from children hospitalized due to respiratory problems, about 3-5 days post 316 infection (Lessler, et al. 2009), while the CMV samples taken from amniotic fluid or newborn 317 urine and saliva are several weeks post infection. Most previous studies have reported a nearly 318 completely homogenous virus population during early stages of infection (Henn, et al. 2012;

319 Zanini, et al. 2015; Kijak, et al. 2017). Nevertheless, in all samples sequenced, AccuNGS captured 320 dozens to thousands of minor transition and transversion variants, mostly segregating at 321 frequencies between 1:100 and 1:10,000 (Figs. S4-S6). These variants are most likely the genetic 322 reservoir that serves to fuel the future evolution of these virus populations.

323 Our results suggest that a prominent factor in determining the intra-host genetic diversity of a 324 sample during acute infection is the number of founder viruses, and in fact we find that the 325 samples with the highest levels of diversity always show evidence for multiple founder infection. 326 A debate has arisen regarding the diversity in CMV samples, where one study has claimed that 327 diversity in this DNA virus is comparable to diversity in RNA viruses (Renzette, et al. 2011), and 328 others suggest that diversity is low in single founder infections and is elevated only when 329 multiple founders/genotypes initiate the infection (Cudini, et al. 2019). Our results strongly 330 support the latter hypothesis, and in fact the high resolution of AccuNGS suggests even lower 331 diversity for single founder new CMV infections than what has been previously reported (Cudini, 332 et al. 2019).

333 For RSV samples, we found no evidence for multiple haplotypes in the samples, which is 334 somewhat surprising given that this is an airborne virus that reaches high titers. Previous work 335 has suggested that the number of founders in RSV infections is $25 \pm 35$ (Lau, et al. 2017). Notably, 
these values were obtained for adults experimentally inoculated with RSV, whereas our study represent natural infection of infants. However, another explanation for this discrepancy is that our data does not allow us to detect infection with multiple founders when they share very similar genotypes, since our haplotype reconstruction method relies on detecting short reads that share two or more mutations. Given the very short duration of RSV infection, it is possible that relatively little genetic diversity is created do novo, and hence very little genetic diversity is transmitted. In other words, an infection may be initiated by several very genetically similar

343 founder genotypes, but we would not detect it. On the other hand, CMV and HIV create longer

344 infections, and the potential to generate and transmit more diverse genotypes within a single

345 carrier is higher.

346 Our results enabled pinpointing the activity of viral hyper-editing by host enzymes, namely 347 APOBEC3 enzymes and ADAR. The latter was particularly prominent in the RSV infections, where 348 we found distinct clusters of mutations matching ADAR context. Surprisingly, the frequency of 349 these clustered mutations was often relatively quite high, as discussed above. There is a debate 350 today surrounding the role of ADAR in viral infections: in some case it was found to be pro-viral 351 whereas in other cases it has been shown to be anti-viral. Pro-viral activity may be plausible 352 when considering that it has been found that ADAR protects cellular transcripts from being 353 detected by intracellular innate immune response (Liddicoat, et al. 2015; Pfaller, et al. 2018).

354 Is it possible that the ADAR signatures we find represent edited viral genomes that escape 355 innate immunity? If so, this would mean these are not DVGs but rather haplotypes with a 356 selective advantage. We consider that this is unlikely: many of the ADAR-like mutations we find 357 are non-synonymous, with often 5-10 such mutations found in a short region. It is highly 358 improbable that so many mutations would yield a "viable" genome, and we hence conclude that 359 ADAR-like hyper-editing yields DVGs. This comes together with evidence for other DVGs 360 (premature stop mutants and point deletions) that also segregate at similar frequencies in the 361 high viral load RSV samples. We find that the most likely explanation for this phenomenon is 362 that the rate of cellular co-infection is very high in some RSV samples, which may be promoted 363 by the syncytia that RSV creates, allowing for complementation of these DVGs. In fact, given 364 rough estimates of RSV mutation rates around $10^{-4}-10^{-5}$, we are able to infer that the rate of co365 infection should be between 0.9 and 0.99 in some of our RSV samples (Wilke and Novella 2003), 366 which is clearly very high. Moreover, we observe that samples with more DVGs are samples with 
367 higher viral loads. Putting this together, we suggest that RSV infections probably occur in a

368 relatively dense site, which allows for so many co-infections, and for the propagation of DVGs.

369 The relationship between viral loads and the levels of DVGs in a sample is quite intuitive. This

370 suggests that in many cases, DVGs may be incorrectly neglected in downstream analyses. For

371 example, the assumption that such mutations occur at mutation selection balance is used to

372 estimate mutation rates and/or fitness costs (Acevedo, et al. 2014; Cuevas, et al. 2015; Theys, et

373 al. 2018), yet high levels of co-infection may lead to deviations from this balance. We suggest

374 that the use of AccuNGS can detect the rate at which DVGs occur, allowing the inference of the

375 co-infection rate. More generally, AccuNGS has the power to uncover the presence and rate of

376 rare genomic events, such as mutations and editing, directly from clinical samples, allowing a

377 better and more detailed understanding of the processes that govern evolution. 


\section{MATERIALS AND METHODS}

\section{Ethics declaration}

382 The study was approved by the local institutional review boards of Tel-Aviv University, Sheba

383 Medical Center (approval number SMC 4631-17 for HIV and SMC 5653-18 for RSV), and

384 Haddasah Medical Center (approval number HMO-063911 for CMV).

\section{Reagents and Kits}

386 Unless stated otherwise, all the described reactions in this paper were carrier with the described

387 products according to the manufacturer's instructions: gel purifications were performed using

388 Wizard ${ }^{\circledR}$ SV Gel and PCR Clean-Up System (Promega, Madison, WI, USA); beads purifications

389 were performed using AMPure XP beads (Beckman Coulter, Brea, CA, USA); concentrations were

390 determined using Qubit fluorometer (Thermo Fisher Scientific, Waltham, MA, USA); reverse

391 transcription (RT) reactions were performed using SuperScript III or IV Reverse Transcriptase

392 (Thermo Fisher Scientific); polymerase chain reactions (PCR) were made using Platinum ${ }^{\text {TM }}$

393 SuperFi ${ }^{\mathrm{TM}}$ high-fidelity DNA Polymerase (Thermo Fisher Scientific) or Q5 high-fidelity DNA

394 Polymerase (New England Biolabs (NEB), Ipswich, MA, USA).

\section{Generation of amplicons from HIV-1 clinical samples}

396 Clinical HIV-1 samples. Plasma samples from nine recently diagnosed HIV-1 patients with viral

397 loads of $5 \times 10^{5}-1 \times 10^{7} \mathrm{cp} / \mathrm{ml}$ were provided by the National HIV Reference Laboratory, Chaim

398 Sheba Medical Center, Ramat-Gan, Israel (Table S6). HIV-1 viral loads were determined and RNA

399 extracted from $0.5 \mathrm{~mL}$ as described above. From each sample a maximum of $300,000 \mathrm{HIV}-1$

400 copies were reverse transcribed using random hexamer priming.

401 HIV-1 control sample. A pLAI.2 plasmid was linearized using the Sall restriction enzyme (NEB)

402 according to manufacturer's instruction. In order to create RNA a PCR reaction was set up using

403 primer containing the sequence of the T7 RNA polymerase promotor 5'TAA TAC GAC TCA CTA

404 TAG CTG GGA GCT CTC TGG CTA AC and the primer pLAI 5761-5782 5'GAG ACT CCC TGA CCC

405 AGA TGC C using Q5 DNA polymerase and the following PCR program: initial denaturation for

$4063 \mathrm{~min}$ at $98^{\circ} \mathrm{C}$, followed by 40 cycles of denaturation for $10 \mathrm{sec}$ at $98^{\circ} \mathrm{C}$, annealing for $30 \mathrm{sec}$ at

$40765^{\circ} \mathrm{C}$ and extension for $3 \mathrm{~min}$ at $72^{\circ} \mathrm{C}$, and final extension for $5 \mathrm{~min}$ at $72^{\circ} \mathrm{C}$. Eight microliters from

408 PCR reaction were carried to in-vitro transcription reaction using HiScribe ${ }^{\mathrm{TM}}$ T7 High Yield RNA

409 Synthesis Kit (NEB) according to the manufacturer's instruction. Finally, the RNA was beads

410 purified (1X ratio). RT was accomplished using random hexamers priming. 
411 Generation of Gag-Pol amplicons. The cDNA of the 9 HIV-1 clinical samples and the HIV-1

412 control sample were used to generate amplicons. To remove excess primers, the resulting cDNA

413 was beads purified ( $0.5 \mathrm{X}$ ratio) and eluted with $30 \mu \mathrm{l}$ nuclease-free water. Fifteen microliters of

414 each sample were then used for PCR amplification using SuperFi DNA polymerase. To amplify

$415 \sim 2500$ bp spanning entire Gag and part of Pol HIV-1 regions (HXB2 coordinates 524-3249, the

416 following primers were used: GAG FW 5'CTC AAT AAA GCT TGC CTT GAG TGC and RT gene RV

417 5'ACT GTC CAT TTA TCA GGA TGG AG, and the following PCR program: initial denaturation for

$4183 \mathrm{~min}$ at $98^{\circ} \mathrm{C}$, followed by 40 cycles of denaturation for $20 \mathrm{sec}$ at $98^{\circ} \mathrm{C}$, annealing for $30 \mathrm{sec}$ at

$41962^{\circ} \mathrm{C}$ and extension for $2.5 \mathrm{~min}$ at $72^{\circ} \mathrm{C}$, and final extension for $5 \mathrm{~min}$ at $72^{\circ} \mathrm{C}$. The amplicons were

420 gel purified and their concentration was determined. The purified products were further used

421 for library construction.

422 Generation of Gag amplicon with primer-ID from HIV9 sample. A primer specific to the entire

423 Gag gene of HIV-1 (HXB2 position 2347) was designed with a $15 \mathrm{~N}$-bases unique barcode

424 followed by a linker sequence for subsequent PCR, Gag ID RT 5'TAC CCA TAC GAT GTT CCA GAT

425 TAC GNN NNN NNN NNN NNN NAC TGT ATC ATC TGC TCC TG TRT CT. Based on the measured

426 viral load and sample concentration, $4 \mu$ l (containing roughly 300,000 HIV-1 copies) were taken

427 for reverse transcription reaction. Reverse transcription was performed using SuperScript IV RT

428 with the following adjustments: (1) In order to maximize the primer annealing to the viral RNA,

429 the sample was allowed to cool down gradually from $65^{\circ} \mathrm{C}$ to room temperature for 10 minutes

430 before it was transferred to ice for $2 \mathrm{~min}$; And (2) The reaction was incubated for $30 \mathrm{~min}$ at $55^{\circ} \mathrm{C}$

431 to increase the overall reaction yield. To remove excess primers, the resulting cDNA was beads

432 purified ( $0.5 \mathrm{X}$ ratio) and eluted with $35 \mu \mathrm{l}$ nuclease-free water. To avoid loss of barcoded primers

433 ("primer-ID"s) due to coverage drop at the ends of a read as a result of the NexteraXT

434 tagmenation process (see "Library construction for Miseq"), the PCR forward primer was

435 designed with a 60bp overhang so the barcode is far from the end of the read. The primers used

436 for amplification were Gag ID FW 5'CTC AAT AAA GCT TGC CTT GAG TGC and Gag ID RV 5'AAG

437 CGA GGA GCT GTT CAC TGC CAT CCT GGT CGA GCT ACC CAT ACG ATG TTC CAG ATT ACG. PCR

438 amplification was accomplished using SuperFi DNA polymerase in a $50 \mu$ l reaction with $33.5 \mu$ of

439 the purified cDNA as input using the following conditions: initial denaturation for $3 \mathrm{~min}$ at $98^{\circ} \mathrm{C}$,

440 followed by 40 cycles of denaturation for $20 \mathrm{sec}$ at $98^{\circ} \mathrm{C}$, annealing for $30 \mathrm{sec}$ at $60^{\circ} \mathrm{C}$ and

441 extension for $1 \mathrm{~min}$ at $72^{\circ} \mathrm{C}$, and final extension for $2 \mathrm{~min}$ at $72^{\circ} \mathrm{C}$. The Gag amplicon was gel 
442 purified and the concentration was determined. The purified product was further used for

443 library construction.

444 Generation of Vif amplicon from HIV9 sample. One and a half microliters from clinical sample

445 HIV9 were reverse transcribed using SuperScript IV RT and random hexamer priming. Five

446 microliters of the purified RT reaction were used to set-up a PCR reaction with SuperFi DNA

447 polymerase to amplify 600 bp region spanning HIV-1 Vif gene using primers vif FW 5'AGG GAT

448 TAT GGA AAA CAG ATG GCA GGT and vif RV 5'CTT AAG CTC CTC TAA AAG CTC TAG TG, and the

449 following program: initial denaturation for $3 \mathrm{~min}$ at $98^{\circ} \mathrm{C}$, followed by 40 cycles of denaturation

450 for $20 \mathrm{sec}$ at $98^{\circ} \mathrm{C}$, annealing for $30 \mathrm{sec}$ at $60^{\circ} \mathrm{C}$ and extension for $30 \mathrm{~min}$ at $72^{\circ} \mathrm{C}$, and final

451 extension for $5 \min$ at $72^{\circ} \mathrm{C}$. The amplicon was gel purified and the concentration was

452 determined. The purified product was further used for library construction.

453 Generation of amplicons from RSV clinical samples

454 Clinical RSV samples. Nasopharyngeal samples of 25 patients hospitalized at Chaim Sheba

455 Medical Center (Table S6) were collected into Virocult liquid viral transport medium (LVTM)

456 (Medical Wire \& Equipment Co, Wiltshire, United Kingdom) and stored at $-70^{\circ} \mathrm{C}$. Five hundred

457 microliters of each sample were extracted and purified using easyMAG according to the

458 manufacturer's instructions. A primer specific to the glycoprotein protein $\mathrm{G}$ was designed with a

$45915 \mathrm{~N}$-bases unique barcode followed by a linker sequence for subsequent PCR, RSV G RT 5'TAC

460 CCA TAC GAT GTT CCA GAT TAC GNN NNN NNN NNN NNN NGC AAA TGC AAM CAT GTC CAA AA.

461 Eight microliters of each sample were reverse transcribed as described in "Generation of Gag

462 amplicon with primer-ID from HIV-1" section.

463 RSV control sample. In the absence of an RSV plasmid, we used human rhinovirus (RV) plasmid

464 (a kind gift by Ann Palmenberg (University of Wisconsin-Madison, WI, USA) to generate a

465 homogeneous control that was run on the same Nextseq run as the RSV samples, similar to the

466 described above. In vitro transcribed RNA underwent RT using SuperScript IV with the following

467 primer: RV14 5' TAC GCA TAC GAT GTT CCA GAN NNN NNN NNN NNN NNN NNN NAT AAA CTC

468 CTA CTT CTA CTC AAA TTA AGT GTC. PCR amplification using Q5 DNA polymerase with the

469 following primers was performed: p3.26 FW 5' TTA AAA CAG CGG ATG GGT ATC CCA C and p3.26

470 RV 5'ATG GTG AGC AAG GGC GAG GAG CTG TTC ACC GGG GTG GTG CTA CGC ATA CGA TGT TCC

471 AGA. 
472 Generation of a glycoprotein-fusion protein amplicon and polymerase amplicons. PCR

473 amplification was accomplished using Q5 DNA polymerase in $50 \mu$ l reactions with $15 \mu$ l of the

474 purified cDNA as input. The following conditions were used for the glycoprotein-fusion protein

475 amplicon: initial denaturation for $3 \mathrm{~min}$ at $98^{\circ} \mathrm{C}$, followed by 40 cycles of denaturation for $20 \mathrm{sec}$

476 at $98^{\circ} \mathrm{C}$, annealing for $30 \mathrm{sec}$ at $58^{\circ} \mathrm{C}$ and extension for $3.5 \mathrm{~min}$ at $72^{\circ} \mathrm{C}$, and final extension for

$4775 \mathrm{~min}$ at $72^{\circ} \mathrm{C}$, using the following primers: Extension FW 5'AAG CGA GGA GCT GTT CAC TGC CAT

478 CCT GGT CGA GCT ACC CAT ACG ATG TTC CAG ATT ACG and RSV G and F RV 5'TGA CAG TAT TGT

479 ACA CTC TTA. For the polymerase amplicon, the following conditions were used: initial

480 denaturation for $3 \min$ at $98^{\circ} \mathrm{C}$, followed by 40 cycles of denaturation for $20 \mathrm{sec}$ at $98^{\circ} \mathrm{C}$,

481 annealing for $30 \mathrm{sec}$ at $60^{\circ} \mathrm{C}$ and extension for $8 \mathrm{~min}$ at $72^{\circ} \mathrm{C}$, and final extension for $5 \mathrm{~min}$ at $72^{\circ} \mathrm{C}$,

482 using the following primers: RSV L FW 5'GGA CAA AAT GGA TCC CAT TAT T and RSV L RV 5'GAA

483 CAG TAC TTG CAY TTT CTT AC. The amplicons were beads purified and joint together at equal

484 amounts. Concentration was determined, and the product was further used for NextSeq library

485 construction.

\section{Generation of a UL54 amplicon from CMV clinical samples}

487 Clinical DNA samples of recently infected patients (see Table S6) were obtained and purified as

488 described previously (Weisblum, et al. 2017). Since CMV is a DNA virus, no reverse transcription

489 step was needed. To generate a homogeneous control sample, the UL54 gene from TB40/E

490 strain was cloned onto a pGEM-t plasmid as described previously (Weisblum, et al. 2017). The

491 samples were diluted to 30,000 copies per PCR amplification reaction, which was set-up using

492 the Q5 DNA polymerase. The primers used to amplify the UL54 gene were UL54 FW 5'TCA ACA

493 GCA TTC GTG CGC CTT and UL54 RV 5'ATG TTT TTC AAC CCG TAT CTG AGC GGC, and the

494 following PCR protocol was executed: initial denaturation for $3 \mathrm{~min}$ at $98 \mathrm{C}$, followed by 38 cycles

495 of denaturation for $20 \mathrm{sec}$ at $98 \mathrm{C}$, annealing for $20 \mathrm{sec}$ at $65 \mathrm{C}$ and extension for $3 \mathrm{~min}$ at $72 \mathrm{C}$, and

496 final extension for $5 \mathrm{~min}$ at $72 \mathrm{C}$. The amplicons were beads purified and their concentrations

497 were determined. The purified products were further used for MiSeq library construction with

498 the following change, $0.875 \mathrm{ng}$ of DNA were used as input for tagmentation instead of $0.85 \mathrm{ng}$.

499 MiSeq/Nextseq Libraries construction

500 PCR fragmentation and indexing of samples for sequencing was performed using the Nextera XT

501 DNA Library Prep Kit (Illumina, San Diego, CA, USA) with the following adjustments to the

502 manufacturer instructions; (1) In order to get a short insert size of 250bp, $0.85 \mathrm{ng}$ of input DNA 
503

was used for tagmentation; (2) No neutralization of the tagmentation buffer was done, as described previously (Baym, et al. 2015); (3) For library amplification of the tagmented DNA, the Nextera XT DNA library prep PCR reagents were replaced with high-fidelity DNA polymerase reagents (the same DNA polymerase that was used for the amplicon generation). The PCR reaction $(50 \mu \mathrm{l}$ total) was set as depicted. Directly to the tagmented DNA, index 1 (i5, illumina, $5 \mu \mathrm{l})$, index $2(\mathrm{i} 7$, illumina, $5 \mu \mathrm{l})$, buffer $(10 \mu \mathrm{l})$, high-fidelity DNA polymerase $(0.5 \mu \mathrm{l})$, dNTPs $(10 \mathrm{mM}, 1 \mu \mathrm{l})$ and nuclease-free water $(8.5 \mu \mathrm{l})$ were added; (4) Amplification was performed with annealing temperature set to $63^{\circ} \mathrm{C}$ instead of $55^{\circ} \mathrm{C}$, as introduced previously (Baym, et al. 2015) and final extension for $2 \mathrm{~min}$; (5) Post-amplification clean-up was achieved using AMPure XP beads in a double size-selection manner (Bronner, et al. 2014), to remove both too large and too small fragments in order to maximize the fraction of fully overlapping read pairs. For the first size-selection, $32.5 \mu \mathrm{l}$ of beads $(0.65 \mathrm{X}$ ratio) were added to bind the large fragments. These beads were separated and discarded. For the second-size selection, $10 \mu \mathrm{l}$ of beads ( $0.2 \mathrm{X}$ ratio) were added to the supernatant to allow binding of intermediate fragments, and the supernatant containing the small fragments was discarded. The intermediate fragments were eluted and their size was determined using a high-sensitivity DNA tape in Tapestation 4200 (Agilent, Santa Clara, CA, USA). A mean size of $\sim 370 \mathrm{bp}$, corresponding to the desired insert size of $\sim 250 \mathrm{bp}$, was achieved; And (6) Normalization and pooling was performed manually.

NextSeq: The longest NextSeq read length is $150 \mathrm{bp}$, we hence selected for a shorter insert size of $270 \mathrm{bp}$, compared to the desired $370 \mathrm{bp}$ insert size for the MiSeq platform. The first size selection of the post-NexteraXT amplification cleanup was performed using $42.5 \mu \mathrm{l}$ of AMPure XP beads (0.85X ratio) (Bronner, et al. 2014).

\section{AccuNGS Development}

The AccuNGS protocol was evaluated using HIV-1 DNA plasmid (Peden, et al. 1991)). Our underlying assumption was that this DNA starting material is homogenous with respect to the theoretical error rate we calculated. This assumption was based on the fact that we used lowcopy plasmids that were grown in Escherichia coli, and only a single colony was subsequently sequenced. The mutation rate of $E$. coli is in the order of $1 \times 10^{-10}$ errors/base/replication (Jee, et al. 2016), and accordingly, error rates in the purified plasmids are expected to be much lower than the original expected protocol mean error of $\sim 10^{-5}$ (Table S7). Table S1 summarizes the different differential sequencing that was performed during the Methods development, in an 
534 attempt to test the contribution of each one of the stages of the protocol to the error rate of

535 the method (see Supplementary Text).

536 Preparation of plasmids. In order to maintain the plasmid stock as homogenous as possible,

537 plasmids were transformed to a chemically competent bacteria cells [DH5alpha (BioLab, Israel)

538 or TG1 [A kind gift by Itai Benhar (Tel Aviv University, Tel Aviv, Israel)]] using a standard heat-

539 shock protocol. Based on the fact that E. coli doubling time is 20 minutes in average using rich

540 growing medium (Sezonov, et al. 2007), a single colony was selected and grown to a maximum

541 of 100 generations. Plasmids were column purified using HiYield ${ }^{\text {TM }}$ Plasmid Mini Kit (RBC

542 Bioscience, New Taipei City, Taiwan) and stored at $-20^{\circ} \mathrm{C}$ until use.

543 Construction of baseline control amplicon. A baseline control amplicon (Table S1) was based on

544 clonal amplification and sequencing of the pLAI.2 plasmid, which contains a full-length HIV-1 $1_{\text {LAI }}$

545 proviral clone (Peden, et al. 1991) (obtained through the NIH AIDS Reagent Program, Division of

546 AIDS, NIAID, NIH: pLAI.2 from Dr. Keith Peden, courtesy of the MRC AIDS Directed Program). The

547 Integrase region of pLAI.2 was amplified using primers: KLV70 - 5'TTC RGG ATY AGA AGT AAA

548 YAT AGT AAC AG and KLV84 - 5'TCC TGT ATG CAR ACC CCA ATA TG (Moscona, et al. 2017). PCR

549 amplification was conducted using SuperFi DNA Polymerase in a 50 $\mu$ l reaction using 20-40 ng of

550 the plasmid as input. Amplification in a thermal cycler was performed as follows: initial

551 denaturation for $3 \mathrm{~min}$ at $98^{\circ} \mathrm{C}$, followed by 40 cycles of denaturation for $20 \mathrm{sec}$ at $98^{\circ} \mathrm{C}$,

552 annealing for $30 \mathrm{sec}$ at $60^{\circ} \mathrm{C}$ and extension for $1 \mathrm{~min}$ at $72^{\circ} \mathrm{C}$, and final extension for $2 \mathrm{~min}$ at $72^{\circ} \mathrm{C}$.

553 In parallel, an alternative PCR reaction was up using Q5 DNA Polymerase. The Integrase

554 amplicon was gel purified and concentration was determined. The purified product was further

555 used for library construction.

556 Construction of AmpR and RpoB control amplicons. For generating the AmpR amplicon, the

557 conserved AmpR gene was amplified from pLAl.2 plasmid using primers: AmpR FW - 5'AAA GTT

558 CTG CTA TGT GGC GC and AmpR RV - 5'GGT CTG ACA GTT ACC AAT GC. PCR amplification was

559 carried out as described above, except for extension duration of $30 \mathrm{sec}$ instead of $1 \mathrm{~min}$.

560 Similarly, the conserved $R p o B$ gene was amplified from the bacteria genome using the following

561 primers: RpoB FW 5'ATG GTT TAC TCC TAT ACC GA and RpoB RV 5'GTG ATC CAG ATC GTT GGT G

562 and the following PCR program: initial denaturation for $3 \mathrm{~min}$ at $98^{\circ} \mathrm{C}$, followed by 40 cycles of

563 denaturation for $10 \mathrm{sec}$ at $98^{\circ} \mathrm{C}$, annealing for $10 \mathrm{sec}$ at $60^{\circ} \mathrm{C}$ and extension for $4 \mathrm{sec}$ at $72^{\circ} \mathrm{C}$, and 
564 final extension for $2 \mathrm{~min}$ at $72^{\circ} \mathrm{C}$. The $\mathrm{AmpR}$ and $\mathrm{RpoB}$ amplicons were gel purified and their

565 concentration was determined. The purified product was further used for library construction.

566 Construction of alternative purification amplicons. The agarose gel purification step of the

567 amplified integrase gene was replaced with other purification methods; (1) For the gel-free

568 sample, the amplified integrase gene was purified using $25 \mu$ l of AMPure XP beads ( $0.5 \mathrm{X}$ ratio),

569 and (2) For the ExoSap sample, $10 \mu \mathrm{l}$ of the amplified integrase gene were mixed with $4 \mu \mathrm{l}$ of

570 ExoSAP-IT ${ }^{\mathrm{TM}}$ PCR Product Cleanup Reagent (Thermo Fisher Scientific) and incubated according to

571 the manufacturer's instructions. No other changes in the generation of amplicon protocol were

572 made.

573 Construction of a PCR-free control amplicon. For the PCR-free sample, 10 $\mathrm{gg}$ of pLAI.2 plasmid

574 was digested using the restriction enzymes: Nhel, Stul and $\mathrm{Xcml}$ (NEB) according to the

575 manufacturer's instructions. A 1500bp fragment containing the integrase region was gel

576 purified and concentration was determined by Qubit. The purified product was further used for

577 library construction.

578 Construction of RNA control amplicons. We used a plasmid containing the full cDNA of

579 Coxsackie virus B3 (CVB3) under a T7 promoter that was a kind gift from Marco Vignuzzi (Institut

580 Pasteur, Paris, France). Ten micrograms of this plasmid were linearized using Sall (NEB), beads

581 purified (0.5X ratio) and then in-vitro transcribed using T7 RNA polymerase (NEB) according to

582 the manufacturer's instructions. The transcribed RNA was bead purified ( $0.5 \mathrm{X}$ ratio) and reverse

583 transcribed with random hexamers using SuperScript III RT. Four microliters of the reverse

584 transcription reaction were used as template for a PCR reaction using primers: CVB FW 5'GGA

585 GAG AAG GTC AAC TCT ATG GAA GC and CVB RV 5'TAC CAC CCT GTA GTT CCC CA, which amplify

586 a $\sim 1500 \mathrm{bp}$ fragment within the CVB genome. PCR reaction (50 $\mu$ l total) was set and amplified

587 using SuperFi DNA polymerase as follows: initial denaturation for $3 \mathrm{~min}$ at $98^{\circ} \mathrm{C}$, followed by 40

588 cycles of denaturation for $20 \mathrm{sec}$ at $98^{\circ} \mathrm{C}$, annealing for $30 \mathrm{sec}$ at $60^{\circ} \mathrm{C}$ and extension for $15 \mathrm{sec}$ at

$58972^{\circ} \mathrm{C}$, and final extension for $2 \mathrm{~min}$ at $72^{\circ} \mathrm{C}$. The CVB amplicon was gel purified and the

590 concentration measured. The purified product was further used for library construction.

591 Alternative library purification methods. For the AMPure XP beads-free sample, post-

592 amplification clean-up by double size-selection was replaced with an agarose gel purification of

593 a 370bp fragment, with no other changes in the library construction protocol. 
594 Alternative tagmentation sample. For the alternative tagmentation sample, a 250bp amplicon

595 within the integrase region was designed, using specific primers with an overhang

596 corresponding to the sequence inserted during the tagmentation step of the NexteraXT DNA

597 library prep kit, NexteraXT free FW 5'TCG TCG GCA GCG TCA GAT GTG TAT AAG AGA CAG ACT

598 TGT CCA TGC ATG GCT TCT C and NexteraXT free RV 5'GTC TCG TGG GCT CGG AGA TGT GTA TAA

599 GAG ACA GTC TAT CTG GCA TGG GTA CCA GCA. PCR reaction was set up using SuperFi DNA

600 polymerase and carried out as follows: initial denaturation for $3 \mathrm{~min}$ at $98^{\circ} \mathrm{C}$, followed by 40

601 cycles of denaturation for $20 \mathrm{sec}$ at $98^{\circ} \mathrm{C}$, annealing for $30 \mathrm{sec}$ at $62^{\circ} \mathrm{C}$ and extension for $15 \mathrm{sec}$ at

$60272^{\circ} \mathrm{C}$, and final denaturation for $2 \mathrm{~min}$ at $72^{\circ} \mathrm{C}$. The PCR product was gel purified and the

603 concentration was measured by Qubit. The purified product was indexed by a succeeding PCR

604 amplification using primers corresponding to i5 and i7 NexteraXT primers (IDT) as mentioned

605 previously (Baym, et al. 2015) at a final concentration of 1uM. The PCR reaction was set up using

606 SuperFi DNA polymerase and amplified as detailed: initial denaturation for $3 \mathrm{~min}$ at $98^{\circ} \mathrm{C}$,

607 followed by 12 cycles of denaturation for $20 \mathrm{sec}$ at $98^{\circ} \mathrm{C}$, annealing for $30 \mathrm{sec}$ at $63^{\circ} \mathrm{C}$ and

608 extension for $30 \mathrm{sec}$ at $72^{\circ} \mathrm{C}$, and final extension for $2 \mathrm{~min}$ at $72 \mathrm{C}$. Size selection was achieved by

609 gel purification of $\sim 370 \mathrm{bp}$ fragments.

610 Sequencing. Sequencing of all synthetic samples, the HIV-1, and CMV samples was performed

611 on the Illumina MiSeq platform using MiSeq Reagent Kit v2 (500-cycles, equal to 250x2 paired-

612 end reads) (Illumina). Sequencing of the RSV-1 samples and a dedicated synthetic sample was

613 performed on the Illumina NextSeq 500 platform using NextSeq 500/550 High Output Kit (300-

614 cycles, equal to $150 \times 2$ paired-end reads) (Illumina).

615 Construction of synthetically mixed populations. A pLAI.2 plasmid was mixed with a pNL4.3

616 plasmid [a kind gift from Eran Bacharach (Tel Aviv University, Tel Aviv, Israel)] using serial

617 dilutions to achieve the following ratios: 1:100, 1:500, 1:1,000, 1:5,000 and 1:10,000 with pLAI.2

618 held as the major strain. Concentrations were measured and each dilution was generated

619 independently to obtain three technical replicas for each ratio. The plasmids mixture was

620 further used for library construction.

\section{Barcode serial dilution test}

622 The pLAI.2 plasmid was used to generate an RNA pool. Five micrograms of this plasmid were

623 linearized using Sall (NEB) and beads purified (0.5X ratio). T7 polymerase promotor was added

624 to the linearized plasmid using T7 extension FW 5'TAA TAC GAC TCA CTA TAG CTG GGA GCT CTC 
TGG CTA AC and the RV 5'GAG ACT CCC TGA CCC AGA TGC C in a PCR reaction using Q5 DNA

626 polymerase with the following program: initial denaturation for $3 \mathrm{~min}$ at $98^{\circ} \mathrm{C}$, followed by 40

627 cycles of denaturation for $10 \mathrm{sec}$ at $98^{\circ} \mathrm{C}$, annealing for $10 \mathrm{sec}$ at $65^{\circ} \mathrm{C}$ and extension for $3 \mathrm{~min}$ at

$62872^{\circ} \mathrm{C}$, and final extension for $5 \mathrm{~min}$ at $72^{\circ} \mathrm{C}$. Four microliters of the reaction was in-vitro

629 transcribed using T7 RNA polymerase according to the manufacturer's instructions. The

630 transcribed RNA was beads purified (0.5X ratio). The purified RNA was serially diluted and for

631 each dilution two reactions were set-up: a primer-ID reaction (as described in the section

632 "Generation of Gag amplicon with primer-ID from HIV-1") and a random hexamer based RT

633 reaction (as described in the section "Construction of RNA control amplicons"). In order to

634 compare these reactions, for the PCR amplification of the random hexamer based RT reaction,

635 we used the following primers: GAG FW 5'CTC AAT AAA GCT TGC CTT GAG TGC and RTgene RV

636 5'ACT GTA TCA TCT GCT CCT GTA TCT corresponding to the primer-ID reaction primers without a

637 barcode. The same PCR program was used for both reactions. The PCR reactions were gel

638 purified and concentration was measured.

\section{Reads processing and base calling}

640 The paired-end reads from each control library were aligned against the reference sequence of

641 that control using an in-house script that relies on BLAST command-line tool (Altschul, et al.

642 1990; Altschul, et al. 1997; Camacho, et al. 2009). The paired-end reads from the clinical

643 samples were aligned against: HIV-1 subtype B HXB2 reference sequence (GenBank accession

644 number K03455.1), RSV reference sample (GenBank accession number U39661), CMV reference

645 sample Merlin (GenBank accession number NC_006273), and then realigned against the

646 consensus sequence obtained for each sample. Bases were called using an in-house script only if

647 the forward and reverse reads agreed and their average Q-score was above an input threshold

648 (30 or 38). At each position, for each alternative base, we calculate mutation frequencies by

649 dividing the number of reads bearing the mutation by loci coverage. Positions were retained for

650 analysis only if sequenced to a depth of at least 100,000 reads. In order to analyze the errors in

651 the sequencing process we used Python 3.7.3 (Anaconda distribution) with the following

652 packages: pandas 0.25.1 (McKinney 2010), matplotlib 3.1.0 (Caswell, et al. 2019), seaborn 0.9.0

653 (Waskom, et al. 2018), numpy 1.16 .3 (Oliphant 2006; Walt, et al. 2011) and scipy 1.2.1 (Jones, et

654 al. 2016). Distributions of errors on control plasmids were compared using two-tailed t-test or

655 two-tailed Mann-Whitney $U$ test. 


\section{Variant calling}

657 In order to facilitate discrimination of true variants from AccuNGS process artifacts, we created

658 a variant caller based on two principles: (i) positions that exhibit relatively high level of error on

659 a control sample are error-prone for the clinical sample as well; and (ii) process errors on a

660 control sample follow a gamma distribution. A gamma distribution was fitted for each mutation

661 type in the control sequence. In order to detect and remove outliers from the fitting process we

662 used the "three-sigma-rule", and positions that showed error higher than three standard

663 deviations from the mean of the fitted distribution were removed. For these rare loci a base was

664 called only if the mutation was more prevalent in the sample by an order of magnitude. For $\mathrm{G}>\mathrm{A}$

665 transition mutations, four distinct gamma distributions were fitted, corresponding for all four

$666 \mathrm{G}>\mathrm{A}$ combinations with preceding nucleotide. Accordingly, for $\mathrm{C}>\mathrm{T}$ transition mutations four

667 gamma distributions were fitted as well, on the four C>T reverse complement mutations of the

668 G>A mutations. For establishing Figures 2-5, variants were called on the input sample only if a

669 mutation was in the extreme $1 \%$ of the relevant gamma distribution fitted using the

670 corresponding control.

\section{Serial dilutions analysis}

672 All dilutions were mapped against the pLAl.2 reference sequence using the default parameters

673 and Q30 as the minimal base quality threshold. Positions with insufficient coverage, defined as

674 having less than 5 times the inverse of the frequency of the minor strain were filtered out, as

675 well as positions with minor variant frequency of above $0.5 \%$ in the homogeneous control

676 sample.

\section{Diversity calculation}

678 Transition nucleotide diversity $\pi$ was calculated per sample using positions with at least 5,000x

679 coverage, using the formulas described in (Zhao and Illingworth 2019), but excluding

680 transversion variants. Sites whose variant frequencies weren't statistically different than the

681 background control were considered as variants of count $=0$ for the calculation.

\section{Haplotypes inference}

683 To infer potential haplotypes, we used a two-step process, illustrated in Figure 6. First we

684 identified all pairs of non-consensus variants (the most common minor variant at each site) that

685 were statistically enriched when present on the same reads. Next we attempted to

686 "concatenate" multiple pairs into a longer stretch based on a shared mutation present in two 
different pairs of variants. In order to find statistically enriched pairs, we considered all sites that may be linked on the same reads (up to 250 bases, which is the maximal length of an Illumina read). For each pair of loci we created a contingency table for the appearance of each variant alone, the two variants together and no variant at all. We then used a one-tailed Fisher exact test to obtain a $p$-value for the pair, and considered only $p$-values lower than $10^{-15}$, to account of multiple testing. From this contingency table we also extracted the frequency at which the two

693 variants co-occur. We repeated the process for all possible pairs of loci. This resulted in many

694 short haplotype stretches of 250 bases spanning two loci each. We then performed

695 "concatenation" of pairs of loci that had (1) at least one shared position and (2) a similar

696 frequency of co-occurrence, defined here as up to an order of magnitude in difference. Such

697 concatenated loci formed a longer stretch and its frequency was calculated as the mean

698 frequency of its components, i.e., the average frequency of all individual pairs added to this

699 stretch so far. For each sample, we iteratively attempted to concatenate all pairs of loci, starting

700 from the highest frequency pair to the least common pair, until no pairs could further merge.

Reference genome

702 Figure 6. Illustration of method for haplotype reconstruction. The method searches for

703 enrichment of pairs of mutations on the same read, and concatenation of enriched reads that

704 share a mutation into a reconstructed minor haplotype. Notably, the concatenation approach is

705 suitable for populations with limited diversity, as is the case in acute infections; in highly diverse

706 populations, many haplotypes may share the "blue" mutation illustrated in the figure.

\section{CODE AVAILABILITY}

708 We have developed the following computational resources that complement the AccuNGS

709 sequencing protocol: 
(a) Base coverage calculator. AccuNGS relies on overlapping read pairs and high Q-scores for both reads of a pair. The calculator receives as input the length of the target regions and the desired coverage, and outputs the recommended number of reads required for sequencing each sample.

(b) Computational pipeline for computing the number of unique RNA molecules sequenced, based on primer-ID barcodes (see Supplementary Text).

(c) Computational pipeline for base-calling and inferring site by site base frequencies.

(d) Computational pipeline for inferring haplotypes.

All resources are freely available at https://github.com/SternLabTAU/AccuNGS.

\section{ACCESSION NUMBERS}

The datasets generated and reported in this study were deposited in the Sequencing Read Archive (SRA, available at https://www.ncbi.nlm.nih.gov/sra), under BioProject PRJNA476431. Frequencies of mutations following base calling will be available in Zenodo (https://zenodo.org/) upon acceptance.

\section{REFERENCES}

Acevedo A, Brodsky L, Andino R. 2014. Mutational and fitness landscapes of an RNA virus revealed through population sequencing. Nature 505:686-690.

Altschul SF, Gish W, Miller W, Myers EW, Lipman DJ. 1990. Basic local alignment search tool. J Mol Biol 215:403-410.

Altschul SF, Madden TL, Schaffer AA, Zhang J, Zhang Z, Miller W, Lipman DJ. 1997. Gapped BLAST and PSI-BLAST: a new generation of protein database search programs. Nucleic Acids Res 25:3389-3402.

Baym M, Kryazhimskiy S, Lieberman TD, Chung H, Desai MM, Kishony R. 2015. Inexpensive multiplexed library preparation for megabase-sized genomes. PloS one 10:e0128036.

Beale RC, Petersen-Mahrt SK, Watt IN, Harris RS, Rada C, Neuberger MS. 2004. Comparison of the differential context-dependence of DNA deamination by APOBEC enzymes: correlation with mutation spectra in vivo. J Mol Biol 337:585-596.

Bishop KN, Holmes RK, Sheehy AM, Davidson NO, Cho SJ, Malim MH. 2004. Cytidine deamination of retroviral DNA by diverse APOBEC proteins. Curr Biol 14:1392-1396. Boucher CA, Bobkova MR, Geretti AM, Hung CC, Kaiser R, Marcelin AG, Streinu-Cercel A, van Wyk J, Dorr P, Vandamme AM. 2018. State of the Art in HIV Drug Resistance: Science and Technology Knowledge Gap. AIDS reviews 20:27-42.

Brodin J, Hedskog C, Heddini A, Benard E, Neher RA, Mild M, Albert J. 2015. Challenges with using primer IDs to improve accuracy of next generation sequencing. PloS one 10:e0119123. Bronner IF, Quail MA, Turner DJ, Swerdlow H. 2014. Improved Protocols for Illumina Sequencing. Curr Protoc Hum Genet 80:18 12 11-42.

Camacho C, Coulouris G, Avagyan V, Ma N, Papadopoulos J, Bealer K, Madden TL. 2009. BLAST+: architecture and applications. BMC bioinformatics 10:421. 
Casadella M, Paredes R. 2017. Deep sequencing for HIV-1 clinical management. Virus Res 239:69-81.

Caswell T, Droettboom M, Hunter J. 2019. matplotlib/matplotlib v3. 1.0, doi: 10.5281/zenodo. 2893252. In. Chen-Harris H, Borucki MK, Torres C, Slezak TR, Allen JE. 2013. Ultra-deep mutant spectrum profiling: improving sequencing accuracy using overlapping read pairs. BMC genomics 14:96. Clutter DS, Jordan MR, Bertagnolio S, Shafer RW. 2016. HIV-1 drug resistance and resistance testing. Infect Genet Evol 46:292-307.

Cudini J, Roy S, Houldcroft CJ, Bryant JM, Depledge DP, Tutill H, Veys P, Williams R, Worth AJJ, Tamuri AU, et al. 2019. Human cytomegalovirus haplotype reconstruction reveals high diversity due to superinfection and evidence of within-host recombination. Proc Natl Acad Sci U S A 116:5693-5698.

Cuevas JM, Geller R, Garijo R, Lopez-Aldeguer J, Sanjuan R. 2015. Extremely High Mutation Rate of HIV-1 In Vivo. PLoS Biol 13:e1002251.

Döring $M$, Büch J, Friedrich $G$, Pironti $A$, Kalaghatgi $P$, Knops $E$, Heger E, Obermeier $M$, Däumer $M$, Thielen $A$, et al. 2018. geno2pheno[ngs-freq]: a genotypic interpretation system for identifying viral drug resistance using next-generation sequencing data. Nucleic Acids Research 46:W271-W277.

Duffy S, Shackelton LA, Holmes EC. 2008. Rates of evolutionary change in viruses: patterns and determinants. Nat Rev Genet 9:267-276.

Gu W, Miller S, Chiu CY. 2019. Clinical metagenomic next-generation sequencing for pathogen detection. Annual Review of Pathology: Mechanisms of Disease 14:319-338.

Hache G, Mansky LM, Harris RS. 2006. Human APOBEC3 proteins, retrovirus restriction, and HIV drug resistance. AIDS reviews 8:148-157.

Henn MR, Boutwell CL, Charlebois P, Lennon NJ, Power KA, Macalalad AR, Berlin AM, Malboeuf $\mathrm{CM}$, Ryan EM, Gnerre S, et al. 2012. Whole genome deep sequencing of HIV-1 reveals the impact of early minor variants upon immune recognition during acute infection. Plos Pathog 8:e1002529.

Huber M, Metzner KJ, Geissberger FD, Shah C, Leemann C, Klimkait T, Boni J, Trkola A, Zagordi O. 2017. MinVar: A rapid and versatile tool for HIV-1 drug resistance genotyping by deep sequencing. J Virol Methods 240:7-13.

Illingworth CJR, Roy S, Beale MA, Tutill H, Williams R, Breuer J. 2017. On the effective depth of viral sequence data. Virus Evol 3:vex030.

Imashimizu M, Oshima T, Lubkowska L, Kashlev M. 2013. Direct assessment of transcription fidelity by high-resolution RNA sequencing. Nucleic Acids Res 41:9090-9104.

Jabara CB, Jones CD, Roach J, Anderson JA, Swanstrom R. 2011. Accurate sampling and deep sequencing of the HIV-1 protease gene using a Primer ID. Proc Natl Acad Sci U S A 108:2016620171.

Jee J, Rasouly A, Shamovsky I, Akivis Y, Steinman SR, Mishra B, Nudler E. 2016. Rates and mechanisms of bacterial mutagenesis from maximum-depth sequencing. Nature 534:693-696. Jones E, Oliphant T, Peterson P. 2016. SciPy: Open source scientific tools for Python, 2001. In. Keele BF, Giorgi EE, Salazar-Gonzalez JF, Decker JM, Pham KT, Salazar MG, Sun C, Grayson T, Wang S, Li H, et al. 2008. Identification and characterization of transmitted and early founder virus envelopes in primary HIV-1 infection. Proc Natl Acad Sci U S A 105:7552-7557. Kennedy SR, Schmitt MW, Fox EJ, Kohrn BF, Salk JJ, Ahn EH, Prindle MJ, Kuong KJ, Shen JC, Risques RA, et al. 2014. Detecting ultralow-frequency mutations by Duplex Sequencing. Nat Protoc 9:2586-2606. 
Kijak GH, Sanders-Buell E, Chenine AL, Eller MA, Goonetilleke N, Thomas R, Leviyang S, Harbolick EA, Bose M, Pham P, et al. 2017. Rare HIV-1 transmitted/founder lineages identified by deep viral sequencing contribute to rapid shifts in dominant quasispecies during acute and early

798 Kircher M, Sawyer S, Meyer M. 2011. Double indexing overcomes inaccuracies in multiplex sequencing on the Illumina platform. Nucleic Acids Research 40:e3-e3. Lau JW, Kim YI, Murphy R, Newman R, Yang X, Zody M, DeVincenzo J, Grad YH. 2017. Deep sequencing of RSV from an adult challenge study and from naturally infected infants reveals heterogeneous diversification dynamics. Virology 510:289-296.

Lessler J, Reich NG, Brookmeyer R, Perl TM, Nelson KE, Cummings DA. 2009. Incubation periods of acute respiratory viral infections: a systematic review. Lancet Infect Dis 9:291-300.

Liddicoat BJ, Piskol R, Chalk AM, Ramaswami G, Higuchi M, Hartner JC, Li JB, Seeburg PH, Walkley CR. 2015. RNA editing by ADAR1 prevents MDA5 sensing of endogenous dsRNA as nonself. Science 349:1115-1120.

Lou DI, Hussmann JA, McBee RM, Acevedo A, Andino R, Press WH, Sawyer SL. 2013. Highthroughput DNA sequencing errors are reduced by orders of magnitude using circle sequencing. Proc Natl Acad Sci U S A 110:19872-19877.

Malim MH. 2009. APOBEC proteins and intrinsic resistance to HIV-1 infection. Philos Trans R Soc Lond B Biol Sci 364:675-687.

McCrone JT, Lauring AS. 2016. Measurements of Intrahost Viral Diversity Are Extremely Sensitive to Systematic Errors in Variant Calling. J Virol 90:6884-6895.

McCrone JT, Woods RJ, Martin ET, Malosh RE, Monto AS, Lauring AS. 2018. Stochastic processes constrain the within and between host evolution of influenza virus. Elife 7:e35962.

McKinney W editor. Proceedings of the 9th Python in Science Conference. 2010.

Meacham F, Boffelli D, Dhahbi J, Martin DI, Singer M, Pachter L. 2011. Identification and correction of systematic error in high-throughput sequence data. BMC bioinformatics 12:451. Moscona R, Ram D, Wax M, Bucris E, Levy I, Mendelson E, Mor O. 2017. Comparison between next-generation and Sanger-based sequencing for the detection of transmitted drug-resistance mutations among recently infected HIV-1 patients in Israel, 2000-2014. J INT AIDS SOC 20.

Newman AM, Lovejoy AF, Klass DM, Kurtz DM, Chabon JJ, Scherer F, Stehr H, Liu CL, Bratman SV, Say C, et al. 2016. Integrated digital error suppression for improved detection of circulating tumor DNA. Nat Biotechnol 34:547-555.

Nielsen R, Yang Z. 1998. Likelihood models for detecting positively selected amino acid sites and applications to the HIV-1 envelope gene. Genetics 148:929-936.

Oliphant TE. 2006. A guide to NumPy: Trelgol Publishing USA.

Parrish CR, Holmes EC, Morens DM, Park E-C, Burke DS, Calisher CH, Laughlin CA, Saif LJ, Daszak P. 2008. Cross-species virus transmission and the emergence of new epidemic diseases. Microbiol. Mol. Biol. Rev. 72:457-470.

Peden K, Emerman M, Montagnier L. 1991. Changes in growth properties on passage in tissue culture of viruses derived from infectious molecular clones of HIV-1LAI, HIV-1MAL, and HIV-1ELI. Virology 185:661-672.

Pfaller CK, Donohue RC, Nersisyan S, Brodsky L, Cattaneo R. 2018. Extensive editing of cellular and viral double-stranded RNA structures accounts for innate immunity suppression and the proviral activity of ADAR1p150. PLoS Biol 16:e2006577.

Preston JL, Royall AE, Randel MA, Sikkink KL, Phillips PC, Johnson EA. 2016. High-specificity detection of rare alleles with Paired-End Low Error Sequencing (PELE-Seq). BMC genomics 17:464. 
Ram D, Leshkowitz D, Gonzalez D, Forer R, Levy I, Chowers M, Lorber M, Hindiyeh M, Mendelson $\mathrm{E}$, Mor O. 2015. Evaluation of GS Junior and MiSeq next-generation sequencing technologies as an alternative to Trugene population sequencing in the clinical HIV laboratory. Journal of virological methods 212:12-16.

Reid-Bayliss KS, Loeb LA. 2017. Accurate RNA consensus sequencing for high-fidelity detection of transcriptional mutagenesis-induced epimutations. Proc Natl Acad Sci U S A 114:9415-9420. Renzette N, Bhattacharjee B, Jensen JD, Gibson L, Kowalik TF. 2011. Extensive genome-wide variability of human cytomegalovirus in congenitally infected infants. Plos Pathog 7:e1001344. Salazar-Gonzalez JF, Bailes E, Pham KT, Salazar MG, Guffey MB, Keele BF, Derdeyn CA, Farmer P, Hunter E, Allen S. 2008. Deciphering human immunodeficiency virus type 1 transmission and early envelope diversification by single-genome amplification and sequencing. Journal of Virology 82:3952-3970.

Samuel CE. 2012. ADARs: viruses and innate immunity. Curr Top Microbiol Immunol 353:163195.

Sanjuan R, Nebot MR, Chirico N, Mansky LM, Belshaw R. 2010. Viral mutation rates. J Virol 84:9733-9748.

Schirmer M, Ijaz UZ, D'Amore R, Hall N, Sloan WT, Quince C. 2015. Insight into biases and sequencing errors for amplicon sequencing with the Illumina MiSeq platform. Nucleic Acids Res 43:e37.

Schirmer M, Sloan WT, Quince C. 2014. Benchmarking of viral haplotype reconstruction programmes: an overview of the capacities and limitations of currently available programmes. Brief Bioinform 15:431-442.

Seibert SA, Howell CY, Hughes MK, Hughes AL. 1995. Natural selection on the gag, pol, and env genes of human immunodeficiency virus 1 (HIV-1). Mol Biol Evol 12:803-813.

Sezonov G, Joseleau-Petit D, D'Ari R. 2007. Escherichia coli physiology in Luria-Bertani broth. J Bacteriol 189:8746-8749.

Tan L, Coenjaerts FE, Houspie L, Viveen MC, van Bleek GM, Wiertz EJ, Martin DP, Lemey P. 2013. The comparative genomics of human respiratory syncytial virus subgroups $A$ and $B$ : genetic variability and molecular evolutionary dynamics. J Virol 87:8213-8226.

Theys K, Feder AF, Gelbart M, Hartl M, Stern A, Pennings PS. 2018. Within-patient mutation frequencies reveal fitness costs of $C p G$ dinucleotides and drastic amino acid changes in HIV. PLoS Genet 14:e1007420.

Walt Svd, Colbert SC, Varoquaux G. 2011. The NumPy Array: A Structure for Efficient Numerical Computation. Computing in Science \& Engineering 13:22-30.

Wang K, Lai S, Yang X, Zhu T, Lu X, Wu Cl, Ruan J. 2017. Ultrasensitive and high-efficiency screen of de novo low-frequency mutations by o2n-seq. Nat Commun 8:15335.

Waskom M, Botvinnik O, O'Kane D, Hobson P, Ostblom J, Lukauskas S, Qalieh A. 2018. mwaskom/seaborn: v0. 9.0 (July 2018). DOI: https://doi. org/10.5281/zenodo 1313201. Weisblum Y, Oiknine-Djian E, Zakay-Rones Z, Vorontsov O, Haimov-Kochman R, Nevo Y, Stockheim D, Yagel S, Panet A, Wolf DG. 2017. APOBEC3A Is Upregulated by Human Cytomegalovirus (HCMV) in the Maternal-Fetal Interface, Acting as an Innate Anti-HCMV Effector. J Virol 91.

Whitmer SLM, Ladner JT, Wiley MR, Patel K, Dudas G, Rambaut A, Sahr F, Prieto K, Shepard SS, Carmody E, et al. 2018. Active Ebola Virus Replication and Heterogeneous Evolutionary Rates in EVD Survivors. Cell Rep 22:1159-1168.

Wilke CO, Novella IS. 2003. Phenotypic mixing and hiding may contribute to memory in viral quasispecies. BMC Microbiol 3:11. 
888 Yang X, Charlebois P, Macalalad A, Henn MR, Zody MC. 2013. V-Phaser 2: variant inference for

889 viral populations. BMC genomics 14:674.

890 Zanini F, Brodin J, Albert J, Neher RA. 2017. Error rates, PCR recombination, and sampling depth

891 in HIV-1 whole genome deep sequencing. Virus Res 239:106-114.

892 Zanini F, Brodin J, Thebo L, Lanz C, Bratt G, Albert J, Neher RA. 2015. Population genomics of

893 intrapatient HIV-1 evolution. Elife 4:e11282.

894 Zanini F, Puller V, Brodin J, Albert J, Neher RA. 2017. In vivo mutation rates and the landscape of

895 fitness costs of HIV-1. Virus Evol 3:vex003.

896 Zhao L, Illingworth CJR. 2019. Measurements of intrahost viral diversity require an unbiased

897 diversity metric. Virus Evol 5:vey041.

898 Zhou S, Bednar MM, Sturdevant CB, Hauser BM, Swanstrom R. 2016. Deep Sequencing of the

899 HIV-1 env Gene Reveals Discrete X4 Lineages and Linkage Disequilibrium between X4 and R5

900 Viruses in the V1/V2 and V3 Variable Regions. J Virol 90:7142-7158.

901 Zhou S, Jones C, Mieczkowski P, Swanstrom R. 2015. Primer ID Validates Template Sampling

902 Depth and Greatly Reduces the Error Rate of Next-Generation Sequencing of HIV-1 Genomic

903 RNA Populations. J Virol 89:8540-8555.

904

\section{ACKNOWLEDGEMENTS}

906 The authors would like to thank Oded Kushnir, Danielle Miller and Yiska Weisblum for valuable

907 support, and for Drs. Neta Zuckerman, Tzachi Hagai and Shaul Pollak for critical reading of the

908 manuscript and helpful discussions.

\section{FUNDING}

910 This work was supported by the SAIA foundation; by the Israeli Science Foundation [1333/16 to

911 AS]; by the German Israeli Foundation [I-1096-411.8-2015 to AS]; by the United-States-Israel

912 Binational Science Foundation [2016555 to AS]; by the Edmond J. Safra center for bioinformatics

913 in Tel Aviv University [to MG, SH, TK]. 